This Accepted author version was available online 2020, $17^{\text {th }}$ of August.

To cite this article: Najib Chouikhi, Federico Brandani, Pluton Pullumbi, Patrick Perré, François Puel (2020)

Biomethane production by adsorption technology: new cycle development, adsorbent selection and process optimization. Adsorption, https://doi.org/10.1007/s10450-020-00250-3

\title{
Biomethane production by adsorption technology: New cycle development, adsorbent selection and process optimization
}

\author{
Najib Chouikhi ${ }^{1,2} \cdot$ Federico Brandani $^{2} \cdot$ Pluton Pullumbi $^{2} \cdot$ Patrick Perre $^{1,3} \cdot$ Francois Puel $^{1}$
}

(supplementary material : pages 21-24 of this author copy)

\begin{abstract}
Gas separation by adsorption processes such as pressure swing adsorption (PSA) presents an attractive alternative for upgrading biogas to biomethane. A new vacuum pressure swing adsorption (VPSA) cycle is proposed for a unit designed to purify pre-cleaned biogas $\left(40 \% \mathrm{CO}_{2}\right.$ and $\left.60 \% \mathrm{CH}_{4}\right)$ in industrial conditions (feed flow rate more than $500 \mathrm{Nm}^{3} / \mathrm{h}$ and large-volume equipment). The process simulations performed to optimize the VPSA unit consider the kinetic separation of the feed components by using an appropriate carbon molecular sieve (CMS) adsorbent having a high kinetic separation selectivity for $\mathrm{CO}_{2}$ with respect to $\mathrm{CH}_{4}$. The designed VPSA unit is composed of five columns that perform three equalization steps. Minimizing methane losses during the regeneration steps necessitates injecting part of the off-gas rich in $\mathrm{CO}_{2}$ at the bottom of the column during the production step to push the $\mathrm{CH}_{4}$ forward. The produced biomethane meets the specification $\left(97 \% \mathrm{CH}_{4}\right)$ of grid injection purity. The developed cycle allows a $\mathrm{CH}_{4}$ recovery of $92 \%$ to be obtained with a specific energy consumption of $0.35 \mathrm{kWh} / \mathrm{Nm}^{3}$, thus meeting the initial requirements for industrial exploitation of VPSA technology for biomethane purification from biogas sources.
\end{abstract}

Keywords: Biomethane production - Biogas upgrade - Methane recovery - Vacuum Pressure - Swing Adsorption Carbon Molecular Sieve - Numerical process simulation

\section{Declarations}

Not applicable

\section{Introduction}

Biogas is a mixture of several gases produced by the anaerobic digestion or fermentation of organic matter (e g., manure, sewage sludge, municipal solid waste biodegradable waste, biodegradable feedstock, etc.). It is characterized by its chemical composition with methane $\left(\mathrm{CH}_{4}\right)$ being the main component, making it a very promising source of energy and considered a viable alternative to fossil sources. The composition of biogas varies with the type of organic matter from which it is derived (Poulleau 2002). However, it is predominately composed of $\left(\mathrm{CH}_{4}\right)$ and carbon dioxide $\left(\mathrm{CO}_{2}\right)$, with relatively small amounts of hydrogen sulfide $\left(\mathrm{H}_{2} \mathrm{~S}\right)$, ammonia $\left(\mathrm{NH}_{3}\right)$, hydrogen $\left(\mathrm{H}_{2}\right)$, nitrogen $\left(\mathrm{N}_{2}\right)$, carbon monoxide (CO), oxygen $\left(\mathrm{O}_{2}\right)$, water vapor, and/or siloxanes and volatile organic compounds (VOC)(Rasi et al. 2007, Rasi 2009).

\section{Affiliations}

Francois Puel

francois.puel@centralesupelec.fr

1 LGPM, Laboratoire de Génie des Procédés et Matériaux, CentraleSupélec, Université Paris-Saclay, 3 rue Joliot-Curie, 91192 Gif-surYvette, France

2 Air Liquide, Paris Innovation Campus. 1, chemin de la Porte des Loges, 78350 Les Loges en Josas, France

3 LGPM, Laboratoire de Génie des Procédés et Matériaux, CentraleSupélec, Université Paris-Saclay, SFR Condorcet FR CNRS 3417 , Centre Européen de Biotechnologie et de Bioéconomie (CEBB), 3 rue des Rouges Terres 51110 Pomacle, France 
The separation or removal of impurities $\left(\mathrm{H}_{2} \mathrm{~S}, \mathrm{~N}_{2}\right)$ and, in particular, the large amount of $\mathrm{CO}_{2}$, is crucial. Some processes used to remove $\mathrm{CO}_{2}$ can also remove minor components. However, in some cases, it is necessary to install pre-treatment units for the removal of these components.

Biomethane can be produced by several technologies already on the market such as adsorption separation (PSA, VPSA processes), absorption separation (physical or chemical absorption), membrane separation (MEMS), membrane contactors, and cryogenic separation (Fougerit et al. 2019; Poulleau 2002; Ryckebosch et al. 2011).

These commercially available technologies for biomethane purification are competitive, all producing highquality biomethane that satisfies the grid specifications (methane purity $>97 \% \mathrm{CH}_{4}$ ). The competition between these technologies is concerning features such as energy consumption, $\mathrm{CH}_{4}$ purity and loss during processing, and capital/operational expenditures. The choice of the specific process, therefore, depends on the specifications of the unit, such as biogas flow rate and quality, presence of impurities and biomethane use (Warren 2012). Gas separation by adsorption technology is widely used for the separation and the purification of gases in a wide range of fields (Sircar 2002; Voss 2005). Processes such as pressure swing adsorption (PSA) are promising tools for biogas upgrading. The adsorptive separation exploits the selective adsorption (thermodynamic or kinetic) of different gas components through specific interactions between the surface of the adsorbent (porous medium) and the adsorbed molecules.

Gas separation by vacuum pressure swing adsorption (VPSA) technology is characterized by its transient and cyclic operation since, after the adsorption phase, the adsorbents have to be partially or completely regenerated for further cyclic use. VPSA processes are rather complex due to the rapidly oscillating dynamics imposed by each cycle. Yet, after a certain number of cycles, the process converges to an established periodic regime ("cyclic steady state" or CSS): In this regime, the state of the system at the beginning of two consecutive cycles is the same. The performance of the VPSA process must be established once the CSS is reached. However, the performance is controlled by many process parameters, such as cycle schedule, column length, fluid velocity, pressure ratio, recycle rate, and kinetics and equilibrium parameters of the adsorbent-adsorbate system under consideration.

Many published studies (Knaebel 2012; Olajossy et al. 2003; Reinhold et al. 1996; Rocha et al. 2017) present a variety of PSA cycle schedules that incorporate a recycling step. They report the positive impact of different possible recycling varieties on the $\mathrm{CH}_{4}$ recovery from landfill gas of the (i) light stream recycling (LR), (ii) heavy stream recycling (HR), (iii) double stream recycling (LR and HR). The literature reports that the cycle with one stage of HR recycling tends to be the most efficient. [Erden et al. 2018] have tested and compared three configurations of recycling purge gas for methane and nitrogen separation with a cycle composed of four steps for two columns.

The most advanced evolutions of PSA and VPSA processes applied to biogas purification are presented for comparison in Table 1, which summarizes the main configuration characteristics of PSA processes and their biomethane purification performance, achieved quite recently. The new cycle configuration reported by (Santos et al. 2011) seems promising for biomethane production. However, a clear limitation relates to the low biogas flow rates under consideration (approximately $30 \mathrm{Nm}^{3} / \mathrm{h}$ ). [Cavenati et al. 2006] have shown that it is useful to use several layers of adsorbents, especially in terms of $\mathrm{CH}_{4}$ productivity. The use of several layers can also be used to remove minor components such as water. Nevertheless, the main drawback relates to the insufficiently low level of $\mathrm{CH}_{4}$ recovery compared to other biogas upgrade technologies such as membrane separation. The use of dual PSA (Augelletti et al. 2017; Grande and Blom 2012) presents an innovative solution for obtaining high-purity $\mathrm{CH}_{4}$ with high recovery for flowrates less than $100 \mathrm{Nm}^{3} / \mathrm{h}$. However, these performances are reached at an increased cost since the proposed solutions use either a higher adsorption pressure (Grande and Blom 2012) or a lower regeneration pressure (0.1bara) (Augelletti et al. 2017) leading to an increase of the specific energy.

Thanks to a simulation approach, the present study aims at designing a new cycle configuration for producing biomethane from biogas meeting the specifications for industrial deployment. We have employed published data of adsorption equilibrium and kinetics of a carbon molecular sieve $3 \mathrm{~K}$ (Takeda) adsorbent reported in the literature by (Cavenati et al, 2005) for performing a rapid study of the impact of the cycle configuration of the VPSA cycle for the kinetic-based separation of $\mathrm{CO} 2$ methane mixture. It also considers realistic constraints for the target separation, such as a methane purity of $97 \%$ and a methane recovery of at least $92 \%$ with the specific energy consumption lower than $0.35 \mathrm{kWh} / \mathrm{m}^{3}$. In addition, feed flow rates ten times higher than the conditions presented in the literature (see Table 1) are considered. Due to the high target methane purity, a VPSA process is necessary. To reduce the cost of purified biomethane production, particular attention is made to decrease the required specific energy by using desorption pressure levels greater than 0.5 bara. A lower desorption pressure would result in a substantial increase in energy consumption. In order to simplify the numerical modeling part, we assumed as a first step that a constant LDF model for the microporous diffusion resistance would give qualitative indications on the most impacting parameters of the cycle. The consideration of the dependence of the kinetic selectivity on the concentration variation will be considered in a second 
stage for completing the study integrating the experimental characterization of the adsorbent and lab-scale bench tests together with new model developments after their validation.

Table 1 Review of published PSA cycles developed for the separation of $\mathrm{CH}_{4} / \mathrm{CO}_{2}$ (Augelletti et al. 2017; Canevesi et al. 2019; Cavenati et al. 2006; Grande and Blom 2012; Khunpolgrang et al. 2015; Santos et al. 2011)

\begin{tabular}{|c|c|c|c|c|c|c|c|c|c|c|}
\hline \multirow[b]{2}{*}{ References } & \multirow[b]{2}{*}{$\begin{array}{c}\text { PSA / VPSA } \\
\text { configuration }\end{array}$} & \multirow[b]{2}{*}{$\begin{array}{c}\text { Adsorb } \\
\text { ents }\end{array}$} & \multirow[b]{2}{*}{$\begin{array}{l}\text { Separation } \\
\text { Mechanism }\end{array}$} & \multicolumn{4}{|c|}{ Operating conditions } & \multicolumn{3}{|c|}{ Performances } \\
\hline & & & & $\begin{array}{l}\mathrm{P}_{\text {ads }} \\
\text { bara }\end{array}$ & $\begin{array}{l}\mathrm{P}_{\mathrm{des}} \\
\text { bara }\end{array}$ & $\begin{array}{c}\text { Feed } \\
\mathrm{Nm}^{3} / \mathrm{h}\end{array}$ & Composition & $\begin{array}{l}\text { Purity } \\
(\%)\end{array}$ & $\begin{array}{c}\text { Recovery } \\
(\%)\end{array}$ & $\begin{array}{c}\text { Spe. } \\
\text { Energy } \\
(\mathrm{kWh} / \mathrm{Nm} 3)\end{array}$ \\
\hline $\begin{array}{l}\text { Grande and } \\
\text { Blom } 2012\end{array}$ & $\begin{array}{l}\text { Two-stage } \\
\text { PSA }\end{array}$ & CMS & $\begin{array}{c}\text { Equilibrium } \\
\& \\
\text { Kinetic }\end{array}$ & $\begin{array}{c}70 \\
\text { (first } \\
\text { stage) } \\
5 \\
\text { (second } \\
\text { stage) }\end{array}$ & $\begin{array}{c}2 \\
\text { (first } \\
\text { stage) } \\
0,5 \\
\text { (second } \\
\text { stage) }\end{array}$ & $80-100$ & $\begin{array}{l}10 \% \mathrm{CO}_{2} \\
90 \% \mathrm{CH}_{4}\end{array}$ & 98 & 99 & -- \\
\hline $\begin{array}{l}\text { Augelletti } \\
\text { et al. } 2017\end{array}$ & $\begin{array}{l}\text { Two-stage } \\
\text { VPSA }\end{array}$ & $\begin{array}{l}\text { Zeolite } \\
5 \mathrm{~A}\end{array}$ & Equilibrium & 6 & 0.2 & 100 & $\begin{array}{l}40 \% \mathrm{CO}_{2} \\
60 \% \mathrm{CH}_{4}\end{array}$ & 97 & 99 & 0.25 \\
\hline $\begin{array}{l}\text { Khunpolgr } \\
\text { ang et al. } \\
2015\end{array}$ & $\begin{array}{c}\text { VPSA } \\
\text { Combined } \\
\text { with nitrogen } \\
\text { regeneration }\end{array}$ & $\begin{array}{l}\text { Zeolite } \\
13 X\end{array}$ & $\begin{array}{c}\text { Equilibrium } \\
\& \\
\text { Kinetic }\end{array}$ & 4 & 0.08 & $2-12$ & $\begin{array}{l}40 \% \mathrm{CO}_{2} \\
60 \% \mathrm{CH}_{4}\end{array}$ & 99 & 93 & 0.24 \\
\hline $\begin{array}{l}\text { Santos et } \\
\text { al. } 2011\end{array}$ & VPSA & $\begin{array}{l}\text { Zeolite } \\
13 \mathrm{X} / \\
\mathrm{CMS}\end{array}$ & $\begin{array}{c}\text { Equilibrium } \\
\& \\
\text { Kinetic }\end{array}$ & 4 & 0.2 & $20-30$ & $\begin{array}{l}33 \% \mathrm{CO}_{2} \\
37 \% \mathrm{CH}_{4}\end{array}$ & 98 & 88 & -- \\
\hline $\begin{array}{l}\text { Canevesi et } \\
\text { al. } 2019\end{array}$ & $\begin{array}{l}\text { VPSA (With } \\
\text { equalization } \\
\text { tank) }\end{array}$ & CMS & Kinetic & 5 & 0.1 & 0.04 & $\begin{array}{l}40 \% \mathrm{CO}_{2} \\
60 \% \mathrm{CH}_{4}\end{array}$ & 97 & 90 & -- \\
\hline
\end{tabular}

\section{Description of the VPSA process}

The reference cycle considered in this study is well studied in $\mathrm{CO}_{2}$ capture and is composed of four columns and an 8-step cycle: two adsorptions, equalization-depressurization, purge provide, blowdown, purge, equalizationpressurization, and feed pressurization (see detailed description in supplementary material). The sequence of the steps of the cycle for a single bed is reported in Figure 1. 


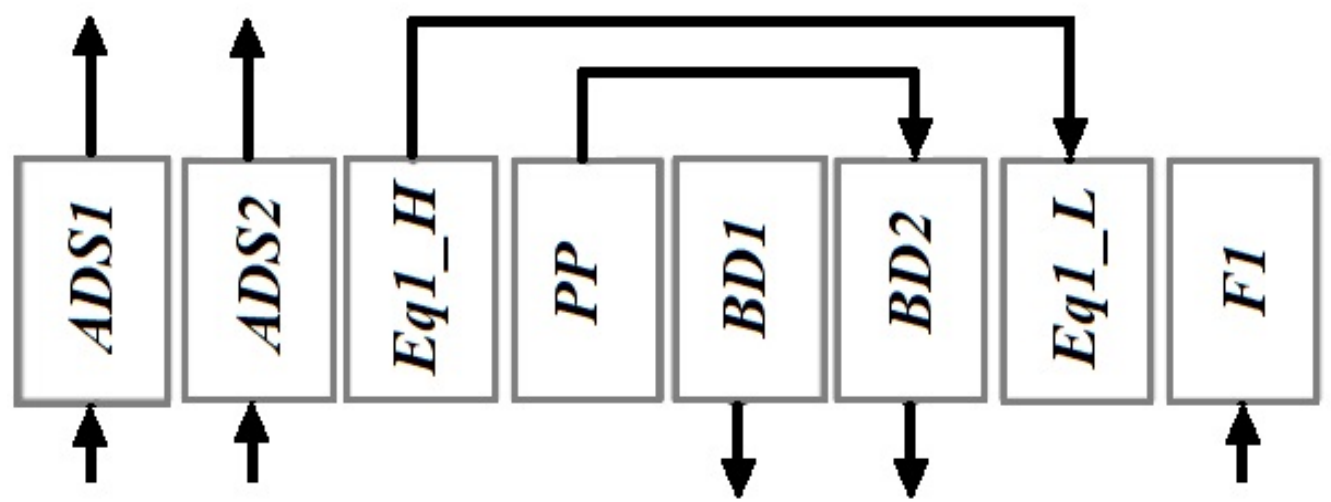

Figure 1: Reference cycle representation based on single bed sequence of 8 steps

(ADS1) Adsorption1, (ADS2) Adsorption2, (Eq1_H) equalization-depressurization, (PP) purge provide, (BD) Blowdown, (Eq1_L) equalization-pressurization, (F1) Feed.

A significant amount of $\mathrm{CH}_{4}$ is lost during the blowdown steps when the reference cycle is considered. Another equalization step was added to improve $\mathrm{CH}_{4}$ recovery. Note that adding successive equalization steps would further increase this recovery rate but at the expense of the increasing complexity of the cycle. Three equalization steps were then selected. Consequently, it was necessary to add another column to the VPSA design. Three equalizations with five columns seemed reasonable from a technological point of view, but the target $\mathrm{CH}_{4}$ recovery indicator remained low compared to the ones obtained by other separation technologies, such as membrane separation. Recycling part of the off-gas, as proposed in the literature, was then adopted as a complement to the three equalizations. However, the recycling configuration was different from the one chosen by (Erden et al. 2018) since, in this study, $\mathrm{CH}_{4}$ is the light component.

We propose a VPSA unit composed of 5 columns with 15 steps. The novelty lies in the configuration of the cycle, which combines three equalizations and a purge gas recycling. The sequence of the cycle steps for a single bed is shown in Figure 2.

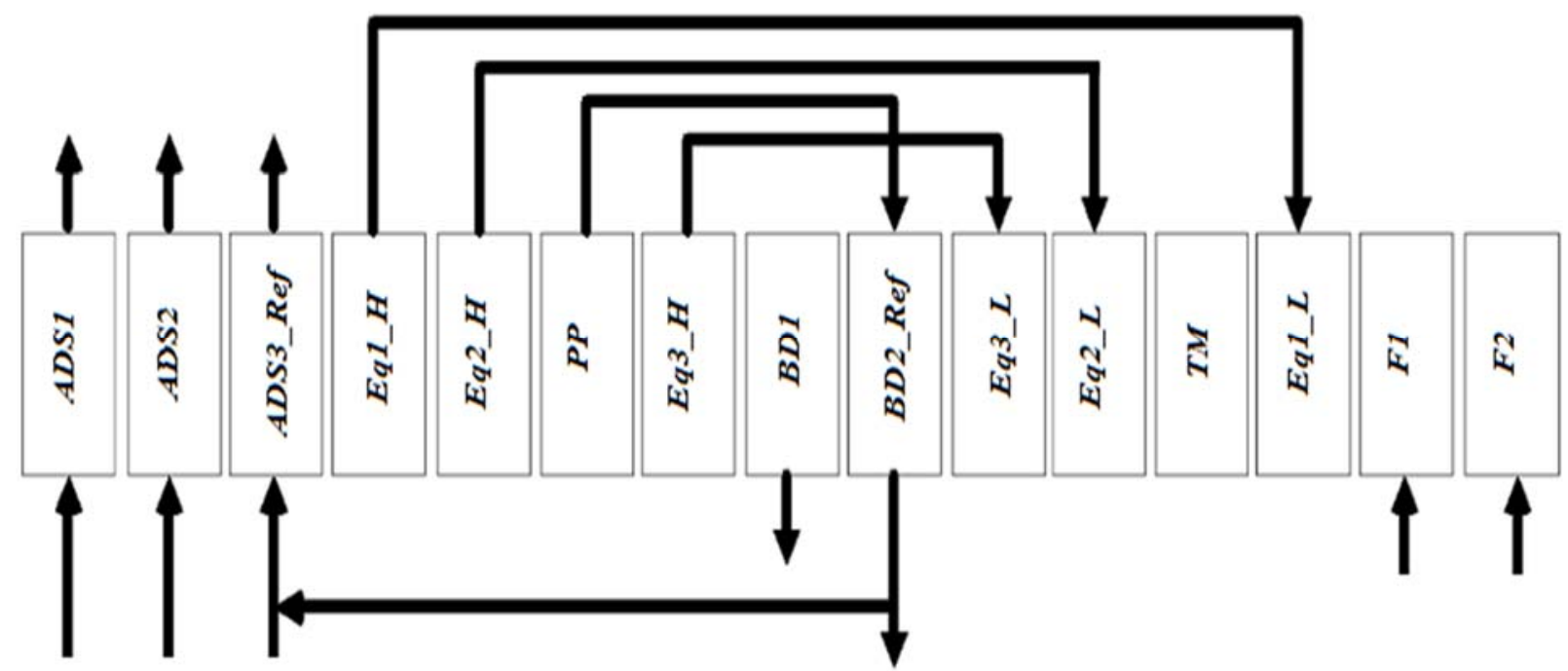

Fig. 2 Cycle representation based on single bed sequence of 15 steps

(ADS1) Adsorption1, (ADS2) Adsorption2, (ADS3_Ref) adsorption 3 reflux, (Eq1_H) equalization-depressurization, (Eq2_H) equalization-depressurization 2, (PP) purge provide,

(Eq3_H) equalization-depressurization 3, (BD1) Blowdown, (BD2_Ref),Blowdown reflux,

(Eq1_L) equalization-pressurization, (Eq3_L) equalization-pressurization 3, (Eq2_L) equalization-pressurization 2, (TM) time out (Eq1_L) equalization-pressurization 1, (F1) Feed 1, (F2) Feed 2 
The representation of the 5-columns and 15-step cycle, indicating the correlation between the columns and the cycle step scheduling known as the cycle chart is reported in Table 2.

Table 2 The cycle chart for the 5-column and 15-step cycle

\begin{tabular}{|c|c|c|c|c|c|c|c|c|c|c|c|c|c|c|c|}
\hline Step & 1 & 2 & 3 & 4 & 5 & 6 & 7 & 8 & 9 & 10 & 11 & 12 & 13 & 14 & 15 \\
\hline Bed 1 & ADS1 & ADS2 & ADS3_Ref & Eq1_H & Eq2_H & $\mathrm{PP}$ & $\mathrm{Eq} 3_{-} \mathrm{H}$ & BD1 & BD2_Ref & Eq3_L & Eq2_L & $\mathrm{TM}$ & Eq1_L & $\mathrm{F} 1$ & $\mathrm{~F} 2$ \\
\hline Bed 2 & Eq1_H & $\mathrm{Eq} 2 \mathrm{H}$ & $\mathrm{PP}$ & $\mathrm{Eq} 33_{-} \mathrm{H}$ & $\mathrm{BD} 1$ & BD2_Ref & $E q 3_{-} L$ & $\mathrm{Eq} 2$ L & TM & $\mathrm{Eq} 1 \_\mathrm{L}$ & $\mathrm{F} 1$ & $\mathrm{~F} 2$ & ADS1 & ADS2 & ADS3_Ref \\
\hline $\operatorname{Bed} 3$ & $\mathrm{Eq} 3_{-} \mathrm{H}$ & BD1 & BD2_Ref & Eq3_L & $\mathrm{Eq} 2 \mathrm{~L}$ & TM & Eq1_L & $\mathrm{F} 1$ & $\mathrm{~F} 2$ & ADS1 & ADS2 & ADS3_Ref & $\mathrm{Eq} 1{ }_{-} \mathrm{H}$ & $\mathrm{Eq} 2 \mathrm{H}$ & $\mathrm{PP}$ \\
\hline $\operatorname{Bed} 4$ & Eq 3 _L & Eq2_L & TM & Eq1_L & $\mathrm{F} 1$ & $\mathrm{~F} 2$ & ADS1 & ADS2 & ADS3_Ref & $\mathrm{Eq} 1{ }_{-} \mathrm{H}$ & $\mathrm{Eq} 2 \mathrm{H}$ & $\mathrm{PP}$ & $\mathrm{Eq} 33_{-} \mathrm{H}$ & BD1 & BD2_Ref \\
\hline $\operatorname{Bed} 5$ & $\mathrm{Eq} 1_{-} \mathrm{L}_{\mathrm{L}}$ & F1 & $\mathrm{F} 2$ & ADS1 & ADS2 & ADS3_Ref & $\mathrm{Eq} 1_{-} \mathrm{H}$ & $\mathrm{Eq} 2 \mathrm{H}$ & $\mathrm{PP}$ & $\mathrm{Eq} 3{ }_{-} \mathrm{H}$ & BD1 & BD2_Ref & $\mathrm{Eq} 3_{-} \mathrm{L}$ & $\mathrm{Eq} 2 \mathrm{~L}$ & TM \\
\hline
\end{tabular}

The 15 steps are regrouped into 5 phases:

The Production phase (PHASE 1) is composed of the following sequence steps:

o Two adsorption production steps (ADS1; ADS2) wherein the biogas is fed to the bottom of the column at high pressure ( 8 bara), the adsorption occurs, and a $\mathrm{CH}_{4}$-rich product is obtained at the top of the column (pure biomethane).

o One adsorption reflux step (ADS3_Ref) wherein a fraction of the off-gas (rich in $\mathrm{CO}_{2}$ ) leaving bottle number 3 during the BD2_Ref step pressurized to 8bara is fed to the bottom of the column. This fraction is called the recycle ratio. The recycle ratio is the off-gas fraction leaving the column 3 during step 9 (BD2_Ref).

The Depressurization phase (PHASE 2) is composed of the following sequence steps:

o Two equalization depressurization steps $\left(\mathrm{Eq1} \_\mathrm{H} \& \mathrm{Eq} 2 \mathrm{H}\right)$, wherein the high-pressure gas present in the interstitial spaces of column 2 at the end of the adsorption phase is used to partially pressurize columns 4 and 5 which are respectively in the Equalization pressurization steps Eq2_L \& Eq1_L.

0 One purge provides step (PP) wherein column 2 (opened at the top and closed at the bottom) is connected to column 3 (which is in the BD2_Ref) to depressurize the column and push the impurities.

The Regeneration phase (PHASE 3) is composed of the following sequence steps:

0 One equalization depressurization step $\left(\mathrm{Eq} 3 \_\mathrm{H}\right)$ wherein the gas at the intermediate pressure, present in the interstitial spaces of column 3 is used to partially pressurize column number 4 from the desorption pressure (under atmospheric pressure) to a pressure greater than the atmospheric pressure.

o One blowdown step (BD1) wherein the regeneration is started. Column 3 (closed in the top and opened in the bottom) is depressurized until atmospheric pressure is reached to start the desorption of the $\mathrm{CO}_{2}$.

o One blowdown and reflux step (BD2_Ref), wherein the regeneration is completed by feeding the column at low pressure using a vacuum pump. A fraction of the desorbed gas is recycled at the feed side of the first column (which is in the ADS3_Ref step)

The Pressurization phase (PHASE 4) is composed of the following sequence steps:

o Two equalization pressurization steps (Eq3_L, Eq2_L) wherein column 4 is partially pressurized with the gas extracted from column 3 during the Eq3_H and column 2 during the Eq2_H).

o A time-out step (T-M) in which column 4 is isolated. The valves are closed at the bottom and top. During this step, the column waits for the other bottles to finish their steps. 
The Pressurization phase (PHASE 5) is composed of the following sequence steps:

0 An equalization pressurization step (Eq1_L), wherein column 5 is partially pressurized with the highpressure gas extracted from column 2 during the Eq1_H step.

o Two Pressurization steps (F1, F2), wherein the column is pressurized with the biogas feed.

\section{Physical modeling}

\subsection{Adsorption equilibrium and kinetics}

Carbon molecular sieve (CMS) adsorbents (CMS 3K, Takeda) are known for their high kinetic selectivity between $\mathrm{CH}_{4}$ and $\mathrm{CO}_{2}$, allowing for these mixtures to be successfully separated by kinetic PSA. CMS absorbents have an average pore size of $3.7 \AA$ (kinetic diameter) (Fougerit et al. 2019). Methane with a pore size greater than $\mathrm{CO}_{2}(3.8$

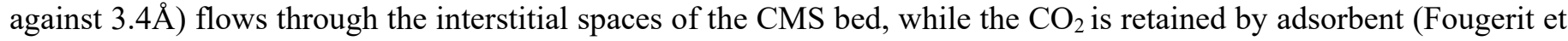
al. 2019).

Several published mathematical models are available to describe adsorption equilibrium. In this work, we have selected the multicomponent extended Langmuir model (Ruthven 1984). The main advantage of this model compared to the traditional Langmuir model lies in its ability to fit the isotherms better.

The quantity adsorbed for a gas $i$ with 3 Langmuir sites is given by equation 1

$$
q_{a d s}^{i}=\frac{q_{s a t 1}^{i} b_{1}^{i} P_{i}}{1+b_{1}^{i} P_{i}}+\frac{q_{s a t 2}^{i} b_{2}^{i} P_{i}}{1+b_{2}^{i} P_{i}}+\frac{q_{s a t 3}^{i} b_{3}^{i} P_{i}}{1+b_{3}^{i} P_{i}}
$$

Wherein $q_{\text {sat } 2}^{i}, q_{\text {sat } 1}^{i} q_{\text {sat } 3}^{i}(\mathrm{Ncc} / \mathrm{g})$ are the saturation quantities of sites 1,2 , and 3 respectively, $b_{1}^{i}, b_{2}^{i}$ and $b_{3}^{i}$ are the curvature of each Langmuir site $\left(\mathrm{bar}^{-1}\right), E_{1}^{i}, E_{2}^{i}$ and $E_{3}^{i}(\mathrm{~J} / \mathrm{mol})$ are the activation energies of component $i$ for each Langmuir site and $P_{i}$ is the partial pressure of component i (bar).

The isotherm parameters of this model for each pure compound on a given adsorbent by determined by inverse analysis of experimental data. The measured data are $q_{a d s}^{i}$ and $P_{i}$ and the parameters to be fitted are $b_{1}^{i}, b_{2}^{i} . b_{3}^{i}$ and $q_{\text {sat } 2}^{i}, q_{\text {sat } 1}^{i}$ $q_{\text {sat } 3}^{i}$ for each site, acknowledging that the coefficients $b_{\mathrm{k}}{ }^{i}$ depend on the temperature according to Arrhenius' law given by equation 2 .

$$
b_{k}^{i}=b_{k}^{i *} e^{\left[\frac{E_{k}^{i}}{R}\left(\frac{1}{T}-\frac{1}{T^{*}}\right)\right]}
$$

A good understanding of the kinetic limitations at different column scales is fundamental to design PSA kinetic based separation. The CMS has a bidisperse structure resulting in both macropores and micropores. Regarding the transport mechanism inside the micropores, several studies have been carried out and an extensive summary can be found in (Qinglin et al. 2004). Three mechanisms have been identified, and they can be described by a pore model where the resistance to diffusion is distributed inside the micropores, a barrier model where the diffusion resistance is at the micropore mouth, and a dual resistance model where the first two mechanisms are combined. Regarding the diffusion inside the micropores its dependency on the adsorbed phase concentration $q^{\wedge} i$ can be described by the Darken's equation (Ruthven 1992):

$$
\mathrm{D}_{\mu, \mathrm{i}}=\mathrm{D}_{\mu, \mathrm{i}, 0} \frac{\mathrm{d} \ln \left(P_{i}\right)}{\mathrm{d} \ln \left(q^{i}\right)}
$$

wherein $\mathrm{D}_{\mu, \mathrm{i}, 0}$ is called the limiting diffusivity, which is the diffusivity in the Henry's law region of the isotherm and $P_{i}$ the partial pressure.

[Qinglin et al. 2003] have shown that a modified dual resistance barrier gave a better representation of the experimental data. This model has been used by (Effendy et al. 2017) to study the kinetic separation of $\mathrm{N}_{2}$ from $\mathrm{CH}_{4}$ via a PVSA process. The purpose of this study is to identify a new process cyle for the $\mathrm{CH}_{4} / \mathrm{CO}_{2}$ separation to provide better $\mathrm{CH}_{4}$ recovery and use of specific energy compared to a given reference cycle (as described in paragraph 2). The implementation of a more detailed kinetic model would require a further work of mathematical modeling and model validation. For this reason for this screening study, we decided to use a simplified bilinear driving force (bi-LDF) model 
used by(Cavenati et al. 2005; Grande and Rodrigues 2007)

The macroporous LDF constants $\left(k_{m a c}^{i}\right)$ were calculated using equation 4 which combines molecular diffusion $D_{m, i}\left(\mathrm{~m}^{2} / \mathrm{s}\right)$ and Knudsen diffusion $D_{k, i}\left(\mathrm{~m}^{2} / \mathrm{s}\right)$ and their values are reported in table 5 (Cavenati et al. 2005).

$$
\mathrm{k}_{\mathrm{mac}}^{\mathrm{i}}=\frac{8 \mathrm{D}_{\mathrm{p}, \mathrm{i}}}{\mathrm{R}_{\mathrm{p}}{ }^{2}} \cdot \frac{1}{\mathrm{D}_{\mathrm{p}, \mathrm{i}}}=\tau\left(\frac{1}{\mathrm{D}_{\mathrm{m}, \mathrm{i}}}+\frac{1}{\mathrm{D}_{\mathrm{k}, \mathrm{i}}}\right) \cdot \mathrm{D}_{\mathrm{k}, \mathrm{i}}=9700 \mathrm{R}_{\mathrm{p}} \sqrt{\frac{\mathrm{T}}{\mathrm{M}}}
$$

The LDF constants for the diffusion of micropores in the CMS adsorbent were calculated using equation 5 wherein $D_{\mu, i}$ is the micropore diffusion, and $\tau$ is the tortuosity factor (2.2 for CMS). For $\mathrm{CH}_{4}$, a dual resistance coefficient has been used, and $k b$ corresponds to the barrier resistance at the micropore mouth coefficient.

$$
k_{\text {mic }}^{C O 2}=\frac{15 D_{\mu, c o 2}}{r_{c}{ }^{2}} \quad k_{m i c}^{C H 4}=\frac{1}{k_{b}+\frac{r_{c}{ }^{2}}{15 D_{\mu, i}}}
$$

\subsection{Column dynamic (mass, energy and momentum balances)}

\section{Assumptions}

The simulation of the PSA process cycle was conducted using a mathematical model (Da Silva et al. 1999; Shafeeyan et al. 2014) for a fixed bed. The main assumptions of the model are:

- The system is $1 \mathrm{D}$ (axial configuration).

- The adsorbent is assumed to be perfectly homogeneous. All the beads of an adsorbent are considered to be identical (either a sphere or a cylinder).

- The porosities are constant, and the solids are perfectly rigid.

- Local thermal equilibrium is assumed, i.e., the gas temperature is equal to the temperature of the beads.

- Gases are considered ideal gases, and the gaseous mixture is supposed to be ideal.

\section{Mass conservation equations}

The mass balance for each component inside a column is described through equation 6 . This expression respectively takes into account (i) the dispersion in the column, (ii) the gas convection, (iii) the accumulation inside the adsorbent, and (iv) the accumulation in the gas phase.

$$
-D l \varepsilon \frac{\partial^{2} C_{i}}{\partial z^{2}}+\frac{\partial}{\partial z}\left(u C_{i}\right)+(1-\varepsilon) S_{i}=-\varepsilon \frac{\partial C_{i}}{\partial t}
$$

wherein $\mathrm{c}_{\mathrm{i}}\left(\mathrm{mol} / \mathrm{m}^{3}\right)$ is the gas concentration of component $\mathrm{i}$ in the column, $\mathrm{Dl}\left(\mathrm{m}^{2} / \mathrm{s}\right)$ is the axial dispersion coefficient, $\mathrm{u}(\mathrm{m} / \mathrm{s})$ is the superficial velocity, $\varepsilon$ is the voidage of the adsorbent bed, and $S_{i}$ is the source term describing the mass transfer between the scale of the column and the scale of the bed.

The expression of $S_{i}$ is as follows:

$$
S_{i}=-\varepsilon_{p} \frac{\partial C_{p i}}{\partial t}+\rho_{g r} \frac{\partial \overline{\bar{q}_{l}}}{\partial t} ; \rho_{g r} k_{m i c}^{i}\left(q_{i}^{*}-\overline{\bar{q}_{l}}\right)+\varepsilon_{p} \frac{\partial C_{p i}}{\partial t}=k_{m a c}^{i}\left(C_{i}-C p_{i}\right)
$$

wherein $\varepsilon_{\mathrm{p}}$ is the porosity of the adsorbent particle, $\rho_{\mathrm{gr}}$ is the density of the grain $C_{p i}$ is the average concentration in the macropores, $\overline{\bar{q}}_{l}$ is the adsorbed quantity integrated both on the volume of the crystal and the particle of adsorbent, and $q_{i}^{*}$ is the adsorbed quantity in the equilibrium.

\section{Energy conservation equation}

The thermal balance in the column is given by equation 8 . This equation respectively considers the heat accumulation in the solid, the heat effect due to compression, the heat convection in the gas phase, the heat conduction in the solid, the heat effects due to adsorption, and the heat transfer rate through the wall.

$$
(\rho C)_{t o t} \frac{\partial T}{\partial t}-\varepsilon \frac{d P}{d t}+\rho_{g} C_{p g} u \frac{\partial T}{\partial z}-\varepsilon \lambda \frac{\partial^{2} T}{\partial z^{2}}=\rho_{b e d} \sum \Delta H_{I} \frac{\partial \overline{\overline{q_{l}}}}{\partial t}+\frac{2 h_{w}}{R_{b e d}}\left(T_{w}-T\right)
$$


wherein $\lambda(\mathrm{W} / \mathrm{K} . \mathrm{m})$ is the thermal conductivity of the solid, $\rho_{\text {bed }}\left(\mathrm{kg} / \mathrm{m}^{3}\right)$ is the packed density of the bed, $h_{w}\left(\mathrm{~W} / \mathrm{m}^{2} \mathrm{~K}\right)$ is the convective heat transfer coefficient at the wall, $T_{w}(K)$ is the temperature of the wall, $\mathrm{R}_{\text {bed }}(\mathrm{m})$ is the radius of the bed, $\Delta \mathrm{H}_{\mathrm{i}}(\mathrm{kJ} / \mathrm{mol})$ is the heat of adsorption of component $\mathrm{i}, \mathrm{C}_{\mathrm{pg}}$ is the calorific capacity of the gas, $\mathrm{C}_{\mathrm{ps}}$ is the calorific capacity of the solid $(\mathrm{kJ} / \mathrm{mol} \mathrm{K})$, and $(\rho C)_{\text {tot }}$ is the total thermal capacity.

\section{Momentum conservation equation}

The flow velocity of a gas in a porous medium generally depends on the pressure drop. For a laminar flow with a Reynolds number less than 1, the velocity is proportional to the pressure gradient (Darcy's law). For faster flows, a non-linear Darcy's law of order 2 can be used.

The linear pressure drop in a porous media of homogeneous and fixed spherical particles is expressed through Ergun's law:

$$
\Delta P=\frac{150 \mu(1-\varepsilon)^{2}}{d_{p}^{2} \varepsilon^{3}} u+\frac{1.75 \rho}{d_{p}} \frac{(1-\varepsilon)}{\varepsilon^{3}} u^{2}
$$

wherein $\varepsilon$ is the porosity of the bed, $\rho$ is the density of the gas $\left(\mathrm{kg} / \mathrm{m}^{3}\right), d_{p}$ is the diameter of the grains (m), $u$ is the superficial velocity $(\mathrm{m} / \mathrm{s}), \mu$ is the dynamical viscosity $(\mathrm{Pa} . \mathrm{s})$ of the fluid $(\mathrm{kg} / \mathrm{m} / \mathrm{s})$, and $\Delta P$ is the linear pressure $\operatorname{drop}(\mathrm{Pa} / \mathrm{m})$.

\section{Boundary conditions at each step}

To solve the system of partial differential equations detailed above, the boundary conditions are needed. They are summarized in Table 3.

For the gas concentration $C_{i}$ and the temperature T, two types of boundary conditions are used at the bottom and the top of the column: either they are imposed for the incoming flow, or they verify the zero-derivative condition for the outgoing flow.

$$
\begin{gathered}
C i]=\text { known } ; T]=\text { known : incoming flow } \\
\left.\left.\frac{\partial C i}{\partial z}\right]=0 ; \frac{\partial T}{\partial z}\right]=0: \text { outgoing flow }
\end{gathered}
$$

For the total pressure, two types of boundary conditions are used, either the pressure is imposed (for example, $\mathrm{P}=8$ bara during the adsorption step) or the pressure verifies the zero-derivative condition when the column is closed.

$$
\begin{gathered}
\left.\frac{\partial P}{\partial z}\right]=0: \text { Column closed } \\
P]=\text { known }: \text { Imposed pressure }
\end{gathered}
$$

The mass flow rate can be fixed using the valve

$$
\rho_{g} u A \mid=k n o w n^{1}
$$


Table 3 Boundary conditions

Bottom of the column $(\mathrm{z}=0)$

Top of the column $(\mathrm{z}=\mathrm{L})$

$\begin{array}{cl}\mathrm{Ci}=\frac{\mathrm{y}_{\text {feed }, \mathrm{i}} \mathrm{P}}{\mathrm{RT}} & \left.\frac{\partial \mathrm{Ci}}{\partial \mathrm{z}}\right]=0 \\ \mathrm{~T}=\mathrm{T}_{\text {feed }} & \left.\frac{\partial \mathrm{T}}{\partial \mathrm{z}}\right]=0\end{array}$

$\mathrm{P}=($ valve cv Reg. $)$

ADS1 \& ADS2

$\mathrm{P}=8$ bara

$\left.\frac{\partial \mathrm{Ci}}{\partial \mathrm{z}}\right]=0$

$\mathrm{Ci}=\frac{\text { Ratio }_{\text {recy }} \text { У }_{\text {BD2ref,i }} \text { P }}{\text { RT }}$

$\left.\frac{\partial \mathrm{T}}{\partial \mathrm{z}}\right]=0$

ADS3_Ref

$\mathrm{T}=\mathrm{T}_{\text {feed }}$

$=$ (valve cv Reg.)

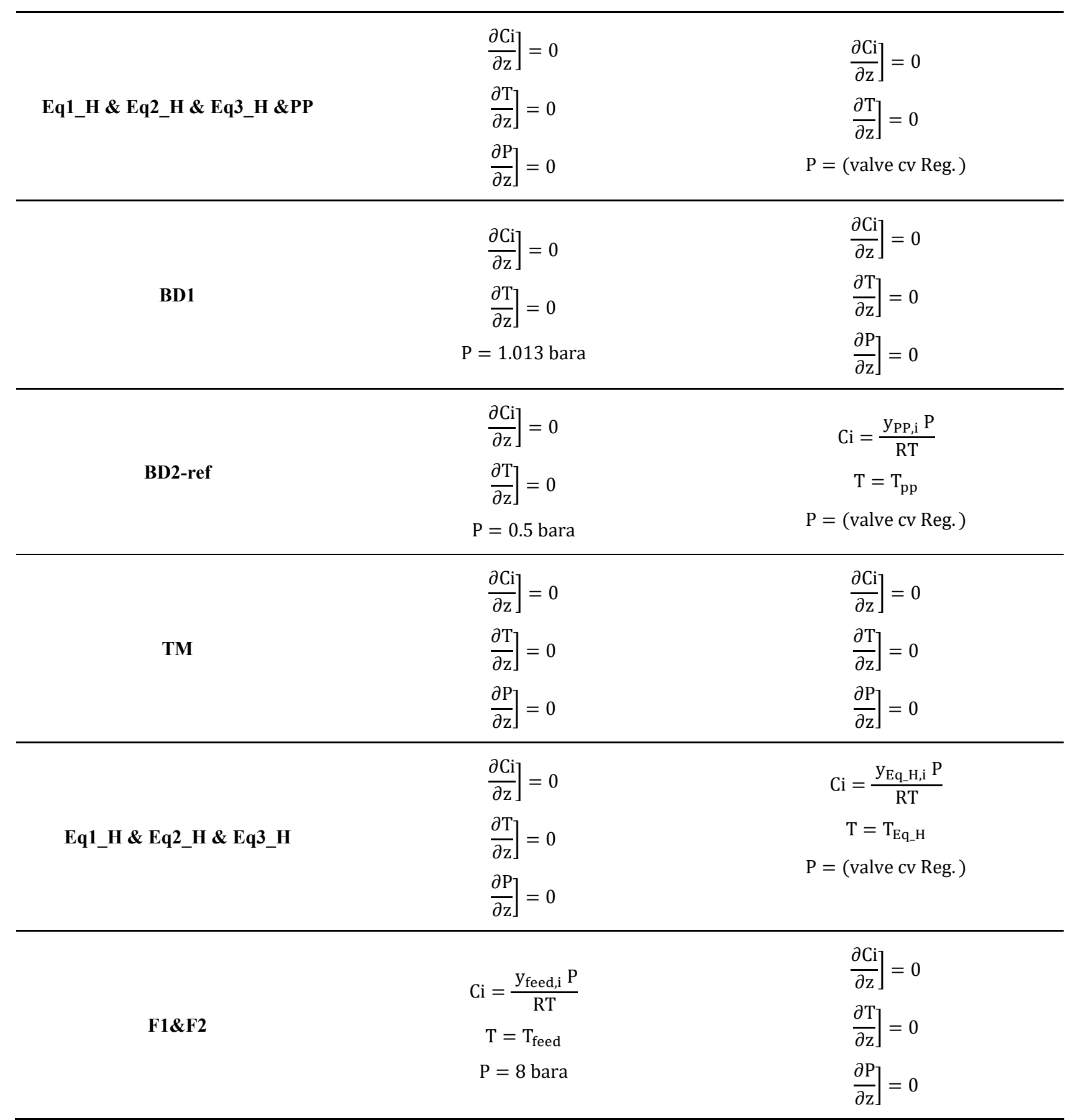




\section{Computational simulation}

A non-isothermal dynamic model was developed in FORTRAN to simulate the VPSA cycle to evaluate the performance of the process in terms of purity and biomethane recovery. The partial differential equations (PDE) of the system, as described in the next section, are discretized by the finite difference method. The DLSODE (Double precision Livermore Solver for Ordinary Differential Equation) FORTRAN subroutine from the package solver (Radhakrishnan K. and Hindmarsh A. C. 1993) is used to solve the system.

\section{Results and discussion}

\subsection{Adsorption Equilibrium and kinetics parameters of pure gases}

The adsorption isotherms of the used CMS adsorbent were measured experimentally utilizing an in-house test bench based on the piezometric/volumetric method. The excess adsorption isotherm is obtained.

This method consists of expanding the known quantities of gas into a volume containing the adsorbent to be analyzed and accurately measuring the different pressures in the system. A mass balance between the injected quantity of molecules and the quantity of molecules in the gas phase after adsorption is used to determine the quantity of adsorbed molecules.

The adsorption equilibrium of pure $\mathrm{CO}_{2}$ and pure $\mathrm{CH}_{4}$ at three different temperatures $(298 \mathrm{~K}, 323 \mathrm{~K}$ and $343 \mathrm{~K})$ are shown in Figure 3. Symbols correspond to the experimental points, and solid lines represent the curve fitted from the Langmuir 3-site model. The three selected temperatures allow us (i) to cover the process temperature range and (ii) to have more precise values of the 3 -site Langmuir model parameters.
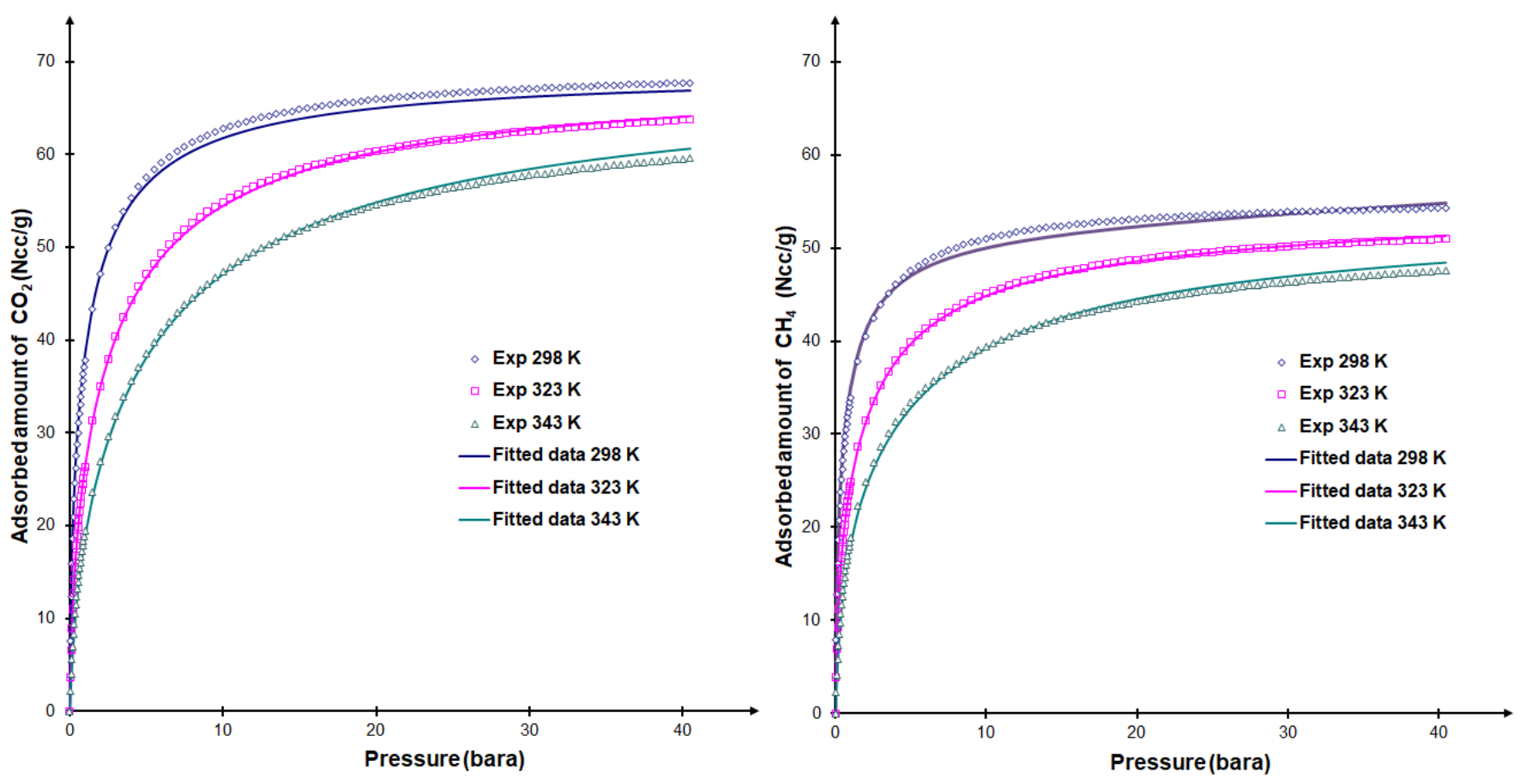

Figure 3: Adsorption equilibrium (excess values) of $\mathrm{CO}_{2}$ (a) and $\mathrm{CH}_{4}$ (b) at $298 \mathrm{~K}, 323 \mathrm{~K}$, and $343 \mathrm{~K}$ (symbol : experimental data; solid line : fitted data)

The results also show that the 3-site Langmuir model allows us to describe the adsorption equilibrium well, and this model has the advantage of having an extension to predict the behavior of other components using single gas data. The fitted values of the model parameters are reported in Table 4 (note that the reference temperature $\mathrm{T}^{*}=293 \mathrm{~K}$ ). However, the measured equilibria tell us that the adsorbent exhibits a low selectivity for $\mathrm{CO}_{2}$ regardless of the temperature. For example, at 10bara and $343 \mathrm{~K}$, the equilibrium is 63 and $44 \mathrm{Ncc} / \mathrm{g}$ adsorbent for $\mathrm{CO}_{2}$ and $\mathrm{CH}_{4}$, respectively. Clearly, this adsorbent cannot be used in an equilibrium-controlled PSA to separate these gases due to the poor selectivity (1.4), at 10 bar and $343 \mathrm{~K}$. 
Table 4 Fitted parameters of the 3-site Langmuir model. $\left(\mathrm{T}^{*}=293 \mathrm{~K}\right)$

\begin{tabular}{cccccccccc} 
& $\begin{array}{c}\mathrm{q}_{\mathrm{s} 1} \\
\left(\mathrm{Ncm}^{3} / \mathrm{g}\right)\end{array}$ & $\begin{array}{c}\mathrm{b}^{*}{ }_{1} \\
(1 / \mathrm{bar})\end{array}$ & $\begin{array}{c}\mathrm{E}_{1} \\
(\mathrm{~J} / \mathrm{mol})\end{array}$ & $\begin{array}{c}\mathrm{q}_{\mathrm{s} 2} \\
(\mathrm{Ncm} / \mathrm{g})\end{array}$ & $\begin{array}{c}\mathrm{b}^{*}{ }_{2} \\
(1 / \mathrm{bar})\end{array}$ & $\begin{array}{c}\mathrm{E}_{2} \\
(\mathrm{~J} / \mathrm{mol})\end{array}$ & $\begin{array}{c}\mathrm{q}_{\mathrm{s} 3} \\
\left(\mathrm{Ncm}^{3} / \mathrm{g}\right)\end{array}$ & $\begin{array}{c}\mathrm{b}^{*}{ }_{3} \\
(1 / \mathrm{bar})\end{array}$ & $\begin{array}{c}\mathrm{E}_{3} \\
(\mathrm{~J} / \mathrm{mol})\end{array}$ \\
\hline $\mathrm{CO}_{2}$ & 20.0 & 14.31 & 35750 & 40.0 & 1.08 & 30762 & 9.0 & 0.25 & 27436 \\
\hline $\mathrm{CH}_{4}$ & 20.0 & 15.32 & 33256 & 30.0 & 1.32 & 31593 & 19.0 & 0.015 & 29107 \\
\hline
\end{tabular}

A good understanding of kinetic limitations at different column scales is fundamental to the design of PSA kinetic-based separation, i.e., an analysis of mass transfer mechanisms in macropores and micropores is necessary. These phenomena are complex because they are based on different mechanisms involving physical and geometric properties of the system, such as pore size or adsorbate concentration. To that purpose, the macropore $\mathrm{k}_{\text {mac }}^{\mathrm{i}}$ and micropore $\mathrm{k}_{\text {mic }}^{\mathrm{i}}$ diffusion constants (equations 3 and 4) were calculated and are reported in Table 5.

Table 5 Calculated kinetic parameters (original data from(Cavenati et al. 2005)

\begin{tabular}{ccccc} 
& $\frac{\mathrm{D}_{\mathrm{p} . \mathrm{i}}}{\mathrm{R}_{\mathrm{p}}^{2}}$ & $k_{b . i}(1 / \mathrm{s})$ & $\mathrm{k}_{\mathrm{mic}}^{\mathrm{i}}(1 / s)$ & $\mathrm{k}_{\mathrm{mac}}^{\mathrm{i}}(1 / s)$ \\
\hline $\mathrm{CH}_{4}$ & 3.07 & $6.9 \mathrm{E}-6$ & $1.85 \mathrm{E}-05$ & 24.5 \\
\hline $\mathrm{CO}_{2}$ & 3.41 & & $1.20 \mathrm{E}-02$ & 27.3 \\
\hline
\end{tabular}

\subsection{Cycle Simulation and optimization}

To evaluate and optimize the process performance in terms of purity and $\mathrm{CH}_{4}$ recovery, four indicators were defined from the simulations of the 5-bed VPSA unit to assess the VPSA performances. These indicators are (i) $\mathrm{CH}_{4}$ recovery, (ii) $\mathrm{CH}_{4}$ purity, (iii) productivity, and (iv) specific energy consumption.

In our case, for the pre-cleaned biogas $(40 \% \mathrm{CO} 2$ and $60 \% \mathrm{CH} 4)$, these criteria are defined as follows:

- Methane recovery is the ratio between the quantity of $\mathrm{CH}_{4}$ produced during the production phase and the quantity of $\mathrm{CH} 4$ used as feed during the adsorption and pressurization steps.

$$
\text { Methane recovery }(\%)=\frac{\mathrm{CH}_{4} \text { product }}{\mathrm{CH}_{4} \text { Feed }}
$$

- Methane purity is calculated as the ratio between the quantity of $\mathrm{CH}_{4}$ produced to the total quantity of the product (considering $\mathrm{CH}_{4}$ and $\mathrm{CO}_{2}$ ).

$$
\text { Methane Purity } \mathrm{CH}_{4}(\%)=\frac{\mathrm{CH}_{4} \text { product }}{\mathrm{CH}_{4} \text { product }+\mathrm{CO}_{2} \text { product }}
$$

- Methane productivity is the amount of $\mathrm{CH}_{4}$ produced per volume of adsorbent per unit of time.

$$
\text { Productivity } \mathrm{CH}_{4}\left(\frac{\mathrm{Nm}^{3}}{\mathrm{~h} * \mathrm{~m}^{3}}\right)=\frac{\mathrm{CH}_{4} \text { product per hour }}{\text { Adsorbent volume }}
$$


- The specific energy consumption is a key parameter for evaluating the economic performance of a VPSA process. It is composed of three terms: the compression energy, the energy consumed by the vacuum pump, and the energy required to recycle pressurization during the regeneration steps.

$$
\text { Specific energy }\left(\frac{\mathrm{kWh}}{\mathrm{Nm}{ }^{3} \text { Methane }}\right)=\frac{\text { Duration }_{\text {cycle }} *\left(\frac{\gamma}{\gamma-1}\right) R T \frac{Q}{\delta}\left[\left(\frac{P h}{P l}\right)^{\frac{\gamma-1}{\gamma}}-1\right]}{\mathrm{CH}_{4} \text { product }}
$$

wherein $\gamma=\frac{C p}{C v} \approx 1.4, \delta$ the mechanical efficiency of the machine (compressor/pump), Q the flow rate, and $\mathrm{Ph}$ and $\mathrm{Pl}$ the high and low-pressure levels, respectively.

Among the four performance indicators listed above, it is necessary to identify which are used as controlled parameters during the simulation and which are used for evaluating and optimizing the process. The feed flow rate is monitored and adjusted during the simulation to reach the target $\mathrm{CH}_{4}$ purity $(97 \%)$. Therefore, the purity is the (only) controlled indicator. The three others, $\mathrm{CH}_{4}$ recovery, specific energy consumption and $\mathrm{CH}_{4}$ productivity, are considered as output variables to be used for process optimization. The aim is to maximize the biomethane recovery, minimize the specific energy consumption and obtain $\mathrm{CH}_{4}$ productivity suitable for an industrial application.

Figure 4 depicts the different column connections taken into consideration in the simulation. Valve V1 connects the column to the feed, valve V2 (3-ways) ensures the purging of the column and the recycling of part of the off-gas, and valve V4 allows the connection between columns during the balancing steps. Valve V3 is open during the production step. It is important to point out that the valve flow coefficient (CV) of each valve, which defines its ability to pass the gas flow, is controlled for each step.

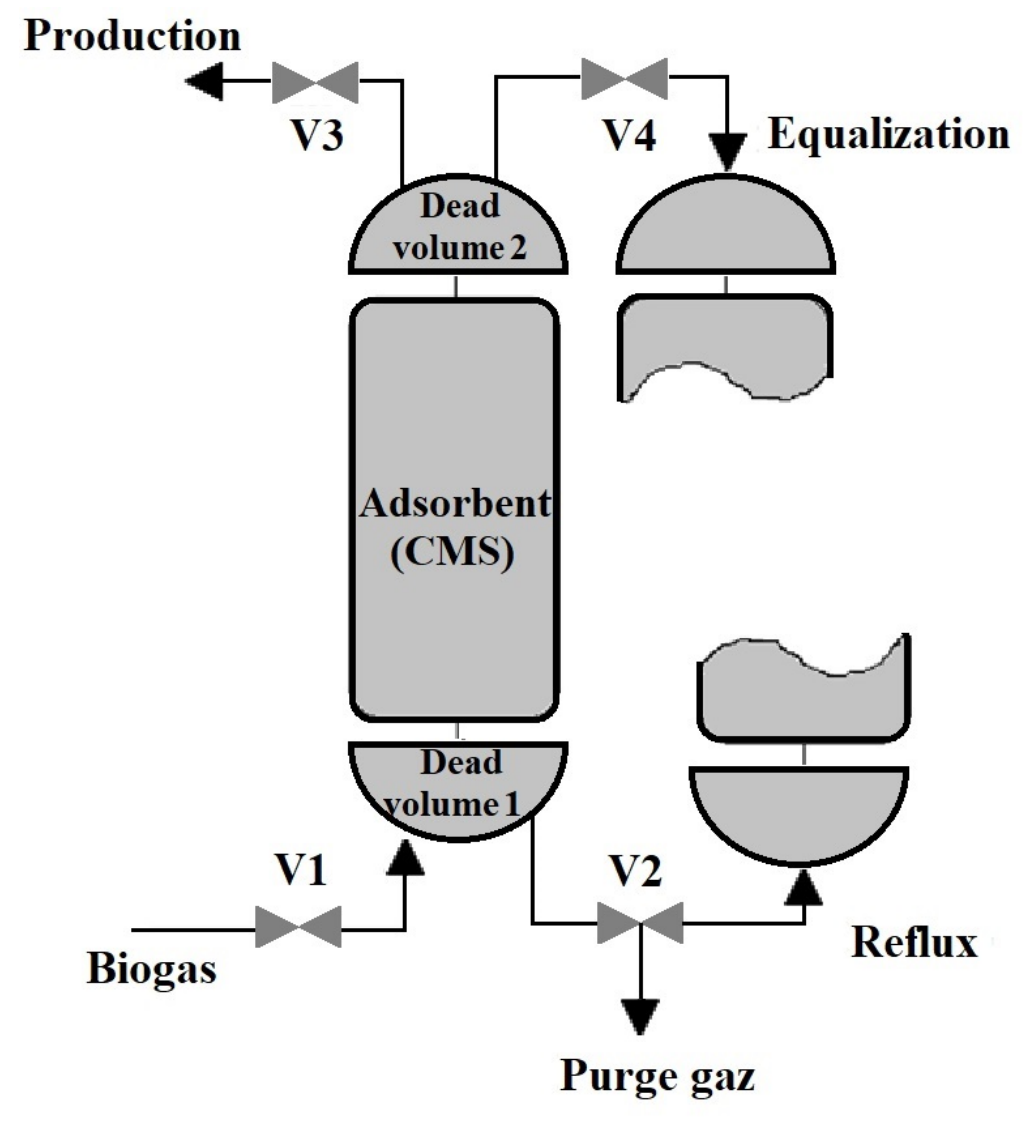

Figure 4: Scheme of the different VPSA column connections

The main operating parameters and column properties are shown in table 6 . The dead volumes 1 and 2 present the void part of the adsorber column, which are necessary for gas distribution. These void volumes don't correspond to the different porosities (bed, pellet, particle). They are used for representing real adsorber ; otherwise, the performances of the unit are overestimated. These dead volumes are reported as a percentage of the adsorbent volume. 
Table 6 Input simulation data

\begin{tabular}{|c|c|}
\hline Bed Length (m) & 2.4 \\
\hline Adsorbent Volume $\left(\mathrm{m}^{3}\right)$ & 3.6 \\
\hline Dead volume $1(\%)$ & 15 \\
\hline Dead volume $2(\%)$ & 8 \\
\hline Adsorbent & CMS \\
\hline Composition $\left(\mathrm{CO}_{2} / \mathrm{CH}_{4}\right)$ moles $(\%)$ & $40 / 60$ \\
\hline Adsorption pressure (bara) & 8 \\
\hline Desorption pressure (bara) & 0.5 bara \\
\hline Number of columns & 5 \\
\hline Target purity (\%) & $97 \%$ \\
\hline Total cycle duration (s) & 725 \\
\hline Bed porosity (-) & 0.33 \\
\hline Pellets porosity (-) & 0.46 \\
\hline Heat capacity $\left(\mathrm{J} \mathrm{kg}^{-1} \mathrm{~K}^{-1}\right)$ & 880 \\
\hline Bed Density $\left(\mathrm{kg} / \mathrm{m}^{3}\right)$ & 715 \\
\hline
\end{tabular}

The parametric study of the effect of the recycle ratio on the $\mathrm{CH}_{4}$ recovery, as well as the criteria of performance obtained with the reference cycle for a fixed purity (97\%) are reported in Table 7 . The simulation results of the reference cycle showed that $26 \%$ of the methane was lost during the two blowdown steps. The first simulation with the new configuration was performed without considering any recycling of purge gas in the adsorption step (ADS3_Ref). This configuration allowed us to recover $6 \%$ more $\mathrm{CH}_{4}$ than in the reference cycle. Nevertheless, $\mathrm{CH}_{4}$ losses remained important during the blowdown steps, especially the second one.

A $2 \%$ gain in $\mathrm{CH}_{4}$ recovery was obtained for each additional recycled $10 \%$ fraction. At the same time, the specific energy consumption and $\mathrm{CH}_{4}$ productivity (and biogas flow rate) decreased. Recycling the purge gas at the end of the adsorption phase leads to a decrease in productivity (see Figure 5) as the recycling gas replaces the feed flowrate. The optimal recycle ratios offer good compromises between $\mathrm{CH}_{4}$ recovery and productivity while keeping a low enough specific energy consumption (at the most $0.35 \mathrm{kWh} / \mathrm{Nm}^{3}$ ) and a large biogas flow rate (at least $500 \mathrm{Nm}^{3} / \mathrm{h}$ ) within the range from 50 to $70 \%$. Thus the $\mathrm{CH}_{4}$ recovery ranges from 89.4 to $93.5 \%$ and the $\mathrm{CH}_{4}$ productivity from 20.6 to $18.7 \mathrm{Nm}^{3} /\left(\mathrm{h} \cdot \mathrm{m}^{3}\right)$. 


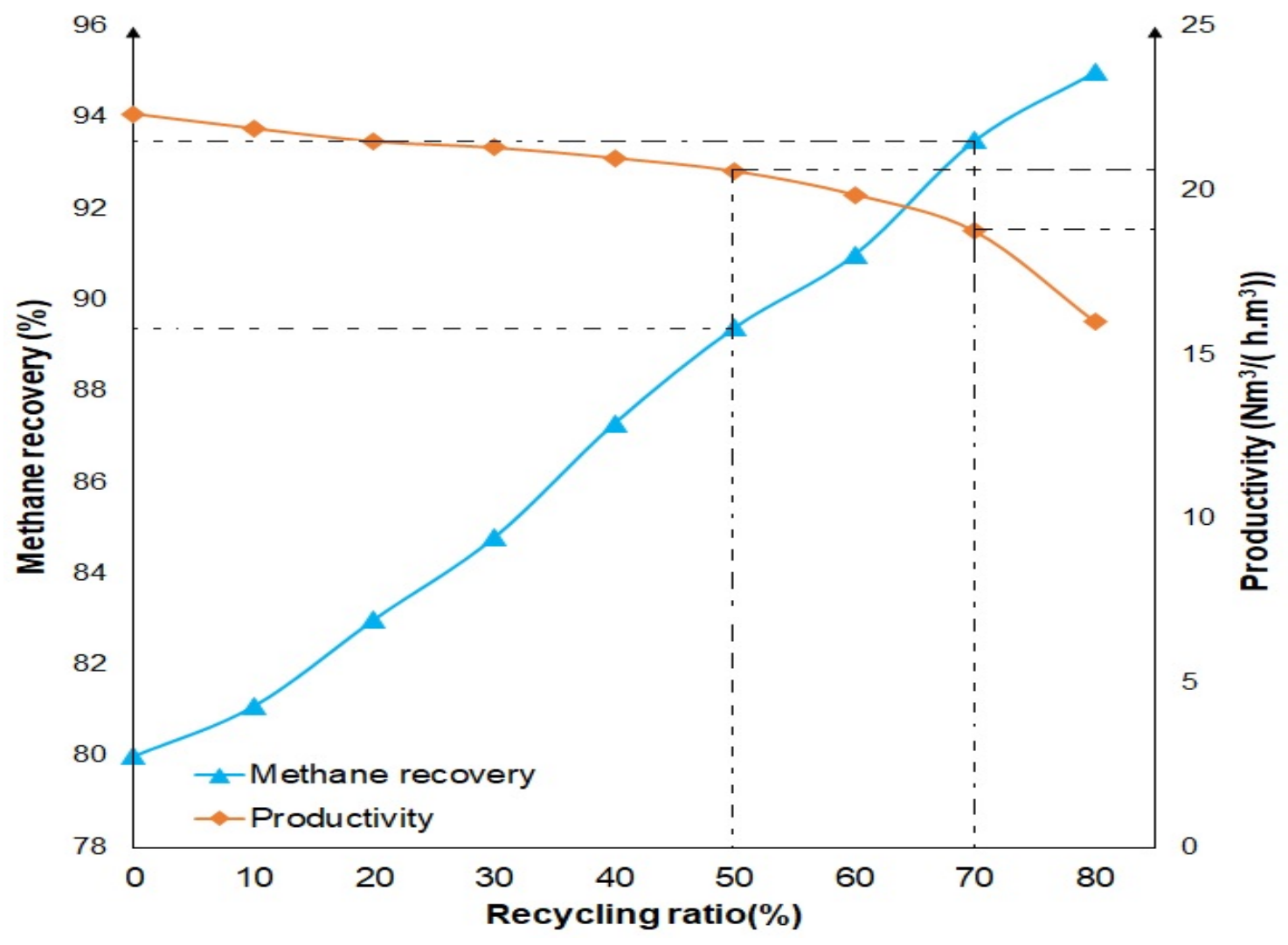

Figure 5 Evolution of the $\mathrm{CH}_{4}$ recovery and productivity with the recycling ratio

Table 7 Effect of the recycling ratio on $\mathrm{CH}_{4}$ recovery for $97 \% \mathrm{CH}_{4}$ purity with the optimized cycle, and comparison with the reference cyle

\begin{tabular}{|c|c|c|c|c|c|c|c|c|c|}
\hline$\underset{\#}{\text { Run }}$ & $\begin{array}{l}\mathrm{P}_{\mathrm{ads}} \\
\text { (bara) }\end{array}$ & $\begin{array}{l}\mathrm{P}_{\text {des }} \\
\text { (bara) }\end{array}$ & $\begin{array}{c}\text { Cycle } \\
\text { duration(s) }\end{array}$ & $\begin{array}{l}\text { Recycle } \\
\text { ratio } \\
(\%)\end{array}$ & $\begin{array}{l}\text { Methane } \\
\text { Purity (\%) }\end{array}$ & $\begin{array}{c}\text { Methane } \\
\text { Recovery } \\
(\%)\end{array}$ & $\begin{array}{l}\text { Productivity } \\
\left(\mathrm{Nm}^{3} /\left(\text { h.m }{ }^{3}\right)\right)\end{array}$ & $\begin{array}{l}\text { Biogas } \\
\text { flowrate } \\
\left(\mathrm{Nm}^{3} / \mathrm{h}\right)\end{array}$ & $\begin{array}{l}\text { Specific energy } \\
\text { consumption } \\
\left(\mathrm{kWh} / \mathrm{Nm}^{3}\right)\end{array}$ \\
\hline
\end{tabular}

\section{Reference cycle}

\begin{tabular}{llllllllll}
\hline 1 & 8 & 0.5 & 680 & 0 & 97 & 74.3 & 32 & 701 & 0.31 \\
\hline 2 & 8 & 0.5 & 725 & 0 & 97 & 80.0 & 22.3 & 971 & 0.48 \\
3 & 8 & 0.5 & 725 & 10 & 97 & 81.1 & 21.9 & 906 & 0.45 \\
4 & 8 & 0.5 & 725 & 20 & 97 & 83.0 & 21.5 & 846 & 0.42 \\
5 & 8 & 0.5 & 725 & 30 & 97 & 84.8 & 21.3 & 790 & 0.41 \\
6 & 8 & 0.5 & 725 & 40 & 97 & 87.3 & 21.0 & 730 & 0.38 \\
7 & 8 & 0.5 & 725 & 50 & 97 & 89.4 & 20.6 & 669 & 0.36 \\
8 & 8 & 0.5 & 725 & 60 & 97 & 91.5 & 19.9 & 599 & 0.33 \\
9 & 8 & 0.5 & 725 & 70 & 97 & 93.5 & 18.7 & 513 & 0.31 \\
10 & 8 & 0.5 & 725 & 80 & 97 & 95.0 & 16.0 & 396 & 0.28 \\
\hline
\end{tabular}


We then investigated the impact of this recycle ratio on different features of the cycle (pressure, temperature, adsorbed amount of $\mathrm{CH}_{4}$ and $\mathrm{CO}_{2}$ ). A comparison is performed between cycles with and without recycle. The chosen recycling ratio is $60 \%$ since it meets the desired performance. Visualizing the cycle features will help us to explain the methane recovery improvement.

Figures $6 \mathrm{a}$ and $6 \mathrm{~b}$ show the pressure profile and the mole fractions of $\mathrm{CO}_{2}$ and $\mathrm{CH}_{4}$ in the gas phase at the bottom of the column without and with recycling, respectively. The pressure profile is the same for both cases, which is consistent as the pressure is a controlled parameter. During the second purge step BD2_Ref, a vacuum pump is used to evacuate the $\mathrm{CO}_{2}$. The pressure was reduced to 0.5 bara to create the condition for gas desorption. The molar fraction of $\mathrm{CH}_{4}$ at the bottom of the column at the end of the ADS3 stage dropped by $40 \%$ due to the recycling of the purge gas.

a)

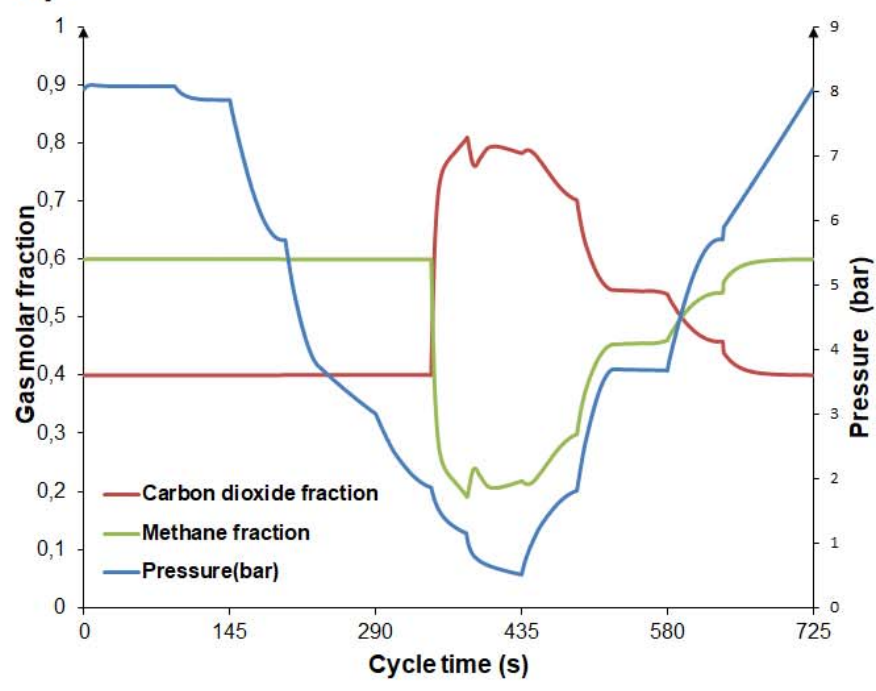

b)

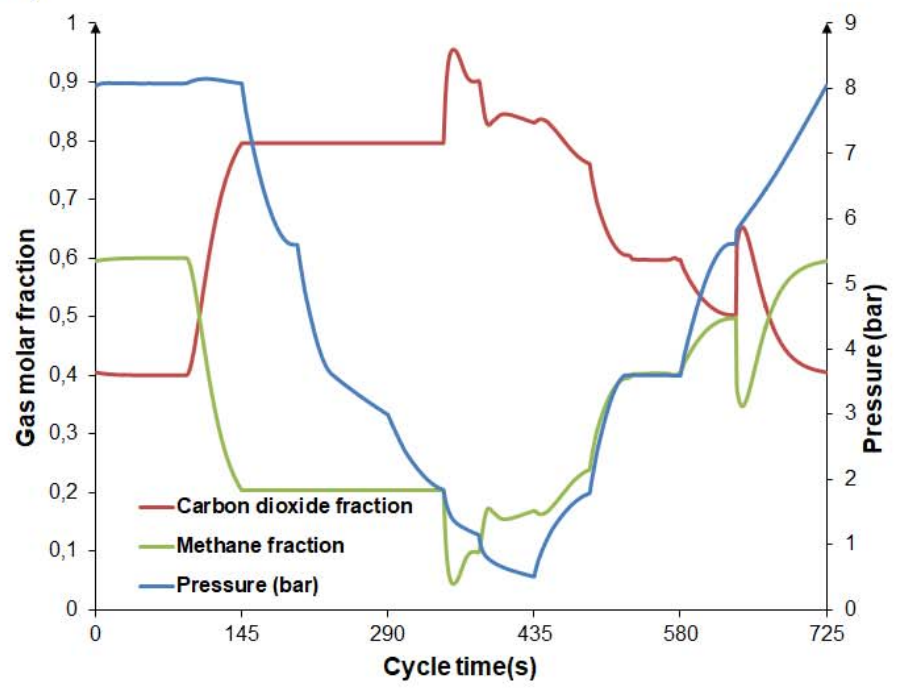

Figure. 6 Pressure profile and gas molar fraction at the bottom of the column: a) without recycling b) with 60\% recycling

The benefits of recycling the purge gas can be observed in Figure 7. At the beginning of the blowdown step (BD1), the fraction of $\mathrm{CH}_{4}$ at the bottom of the column is $40 \%$ lower when the recycling is implemented. This difference declines progressively down to $12 \%$ at the beginning of BD2_Ref. By recycling $60 \%$ of the off-gas (rich in $\mathrm{CO}_{2}$ ), the $\mathrm{CO}_{2}$ pushes the $\mathrm{CH}_{4}$ already adsorbed upwards during the ADS3_Ref stage. The total loss of $\mathrm{CH}_{4}$ occurs during these two blowdown steps. It is clear that decreasing the $\mathrm{CH}_{4}$ composition in these two streams improves its recovery. 


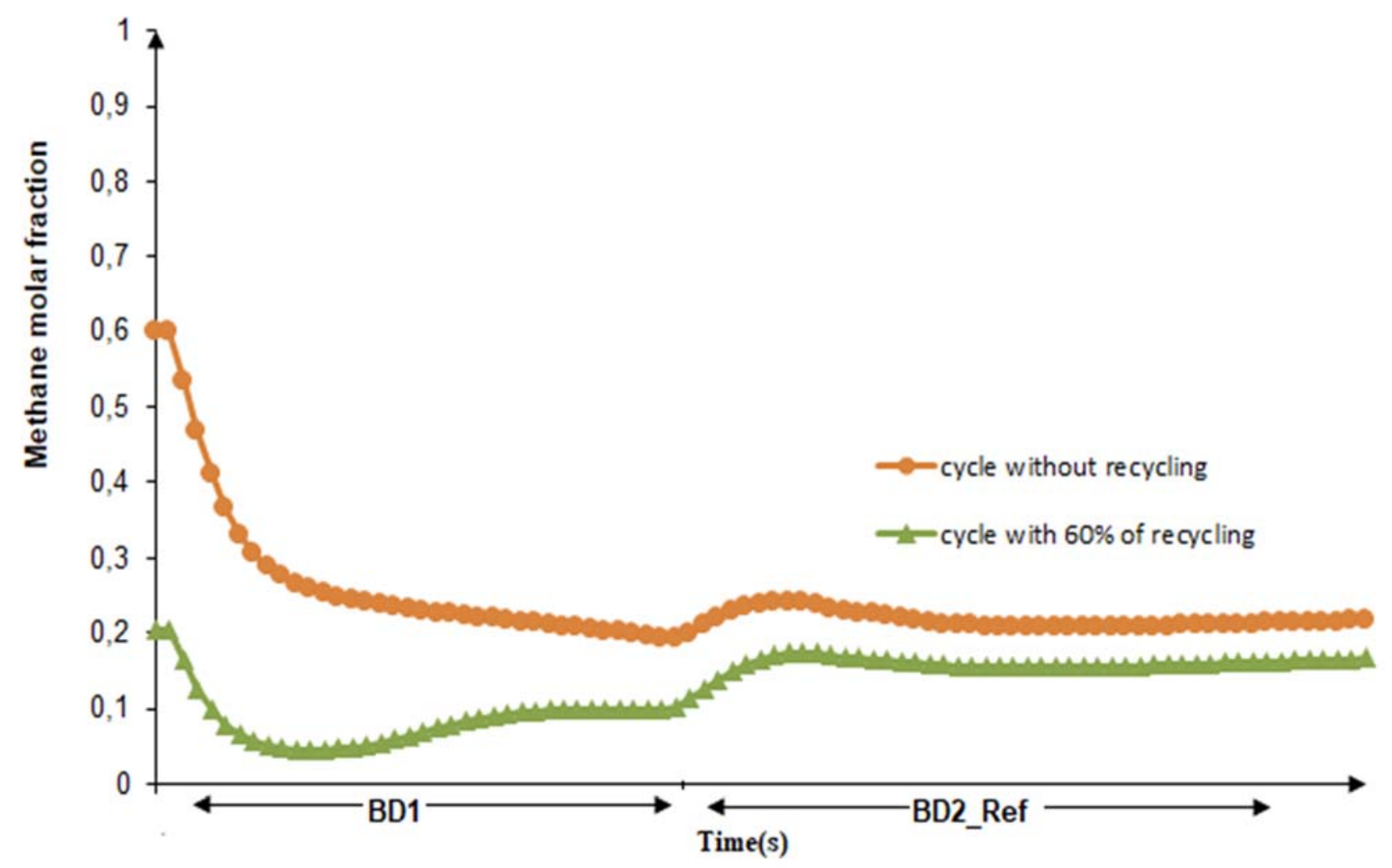

Figure. 7 Methane molar fraction at the bottom of the column during purge steps (BD1 and BD2_Ref)

The temperature profiles at three different axial positions in the column $(\mathrm{z}=0.5,1$, and $2 \mathrm{~m})$ without and with recycling are shown in Figures $8 \mathrm{a}$ and $8 \mathrm{~b}$, respectively. The temperature variations are similar at the top of the column regardless of the configuration. During the adsorption steps, the temperature increased by $15 \mathrm{~K}$ from the initial value, especially around $\mathrm{z}=1 \mathrm{~m}(\mathrm{z} / \mathrm{l}=0.4)$, which corresponds to the maximum adsorbed amount of $\mathrm{CO}_{2}$. As expected, the temperature decreased during the regeneration steps. The highest temperature level is higher when the recycler is operating since the $\mathrm{CO}_{2}$ adsorbed amount is more important. 

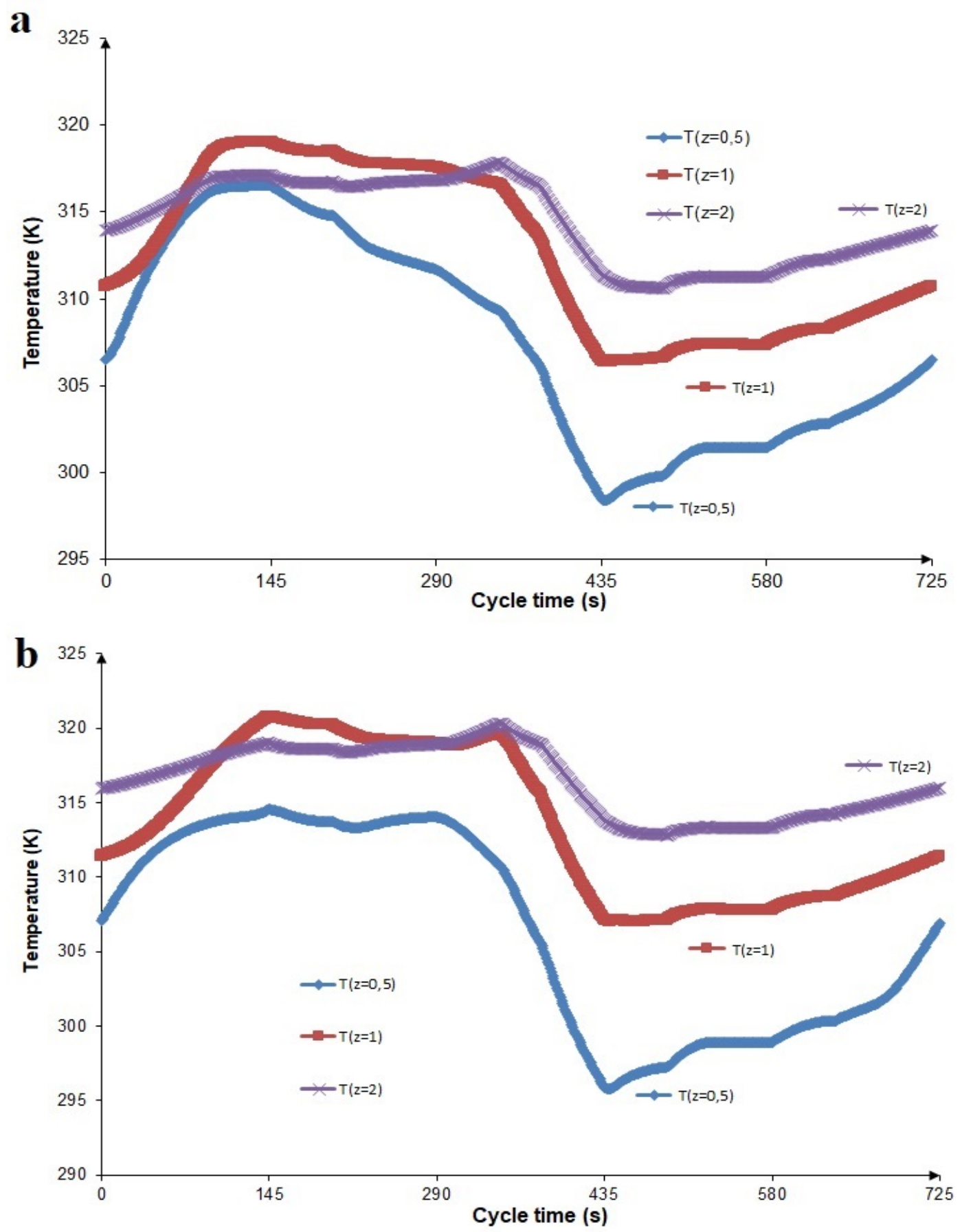

Figure. 8 Temperature profile at three different axial positions a) without recycling and $b$ ) with $60 \%$ recycling

Figures $9 \mathrm{a}$ and $9 \mathrm{~b}$ present the adsorbed amount of $\mathrm{CH}_{4}$ at the end of each step as a function of the axial position without or with recycling, respectively. The increase of $\mathrm{CH}_{4}$ adsorbed in the CMS in the axial position reflects the composition of the gas in the column, which is increasingly purer. The $\mathrm{CH}_{4}$ profiles are quite similar, depending on the configuration. The maximum amount of $\mathrm{CH}_{4}$ absorbed is higher with recycling $(20.4 \mathrm{Ncc} / \mathrm{g}$ instead of $119.5 \mathrm{Ncc} / \mathrm{g})$. The main difference between the adsorbed amount of $\mathrm{CH}_{4}$ is observed in the first lower section of the column. The unexpected result is the absence of variation of $\mathrm{CH}_{4}$ adsorbed between steps. At cyclic steady state, the $\mathrm{CH}_{4}$ already adsorbed on the CMS is not desorbed during the generation step. Additional simulations (see supplementary material) were performed using a lower desorption pressure level $(0.1$ bara). The impact of this operating parameter was not significant. As we will see in the next section, only the amount of adsorbed $\mathrm{CO}_{2}$ varies from one step to the other. This result was already reported by (Santos et al. 2011) under similar situation (VPSA process and use of CMS for biogas upgrading). However, the adsorbed quantity is 10 times higher in our study since the feed velocity level is 20 times lower $(0.1 \mathrm{~cm} / \mathrm{s}$ instead of $2.3 \mathrm{~cm} / \mathrm{s})$. 

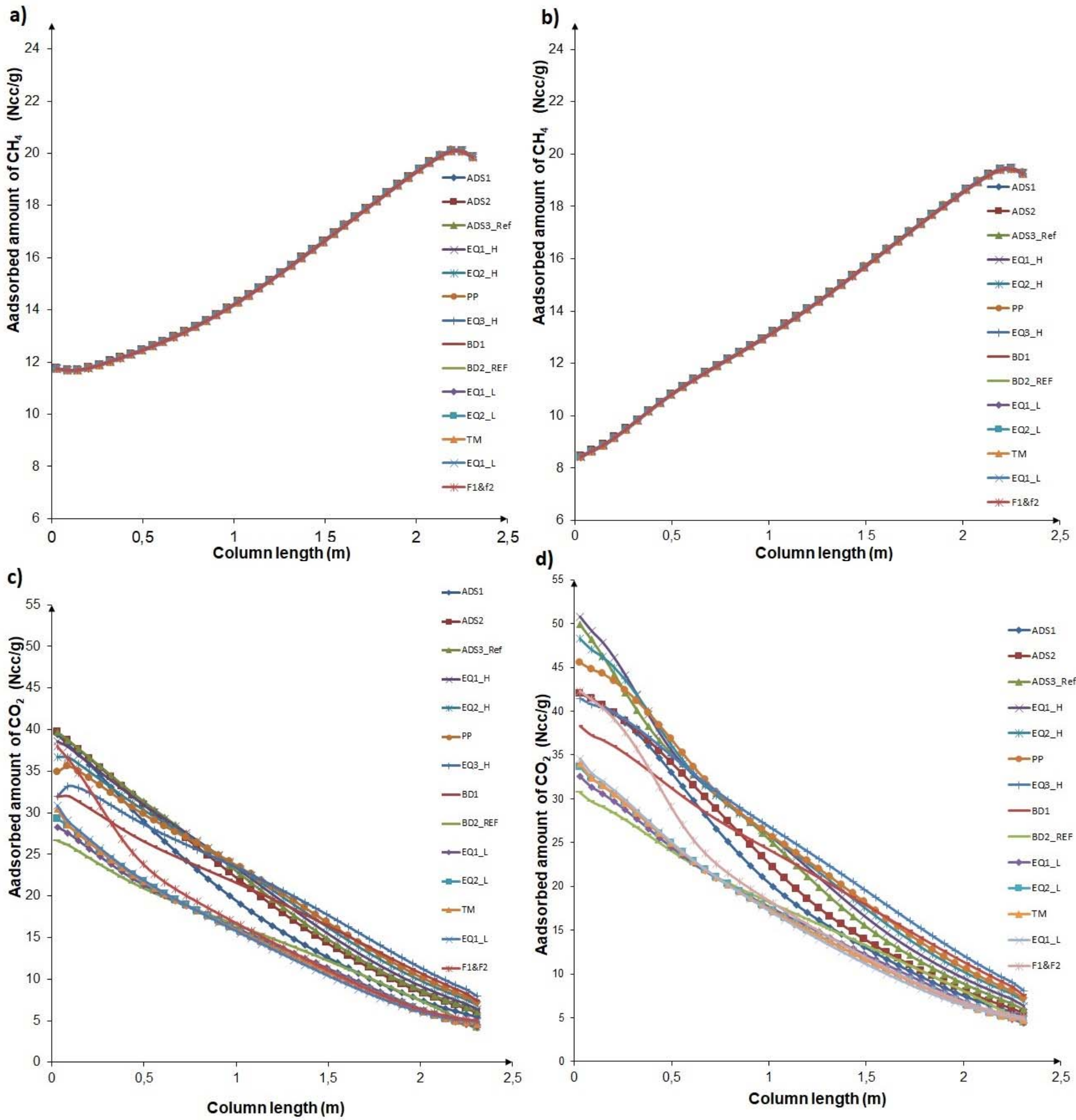

Figure. 9 Adsorbed amount of $\mathrm{CH}_{4}$ and $\mathrm{CO}_{2}$ at the end of each step as a function of the axial position without or with recycling: a) $\mathrm{CH}_{4}$ adsorbed amount without recycling, b) $\mathrm{CH}_{4}$ adsorbed amount with $60 \%$ recycling, c) $\mathrm{CO}_{2}$ adsorbed amount without recycling, and d) $\mathrm{CO}_{2}$ adsorbed amount with $60 \%$ recycling

Figures 9.c and 9.d show the amount of $\mathrm{CO}_{2}$ adsorbed at the end of each step without and with recycling, respectively. It is clear that the adsorption profile of $\mathrm{CO}_{2}$ is reverse with that of $\mathrm{CH}_{4}$. The highest values of adsorbed $\mathrm{CO}_{2}$ are found at the bottom of the column. Unlike $\mathrm{CH}_{4}$, the variations in the amount of $\mathrm{CO}_{2}$ adsorbed between steps are significant, reflecting the greater kinetic ability of this component to adsorb and desorb with this adsorbent. We can also note that the implementation of recycling increases the variations of adsorbed quantities along the column and from one stage to another. It is during the ADS3_Ref step that the $\mathrm{CO}_{2}$ adsorbed amount at the bottom of the column is at its maximum. This value is $12 \mathrm{Ncc} / \mathrm{g}$ higher with recycling, which justifies the lower quantity of $\mathrm{CH}_{4}$ adsorbed at the bottom of the column (see Figure 9a). On the other hand, it can be seen that at the end of the purge stages (BD2 ref), the quantity of $\mathrm{CO}_{2}$ adsorbed is slightly higher with recycling (difference of $+2.2 \mathrm{Ncc} / \mathrm{g}$ ), which means that the $\overline{\mathrm{C}} \mathrm{MS}$ desorbs less $\mathrm{CO}_{2}$. With the same desorption capacity, a slightly longer purge time is required to desorb the additional amount of adsorbed $\mathrm{CO}_{2}(12 \mathrm{Ncc} / \mathrm{g})$. 


\section{Conclusion}

In this work, we have considered the effect of VPSA cycle arrangement for biomethane production. The resulting VPSA unit composed of five columns is proposed as the best solution. It includes one recycle and three equalization steps for improving the biogas upgrade with a $\mathrm{CH}_{4}$ purity target of $97 \%$. Their performances are better than those obtained with a reference cycle composed of four columns and eight steps. However, the assumption of constant micropore diffusivities used for this simulation study as a first approximation for the cycle screening study needs to be revisited at a further stage with the more detailed model as described in paragraph 3.1.

The initial analysis of the simulation results of the cycle without recycling showed that $20 \%$ of the $\mathrm{CH}_{4}$ was lost during the purge steps, especially the second one. To minimize loss, a partial modification of the cycle configuration, by including a recycle step, was adopted. Part of the purge gas (rich in $\mathrm{CO}_{2}$ ) flowing from the second purge step BD2_Ref was pressurized and injected at the bottom of the column in the last production period ADS3_Ref.

A series of simulations with different recycle ratio values were conducted to evaluate the impact of the recycling. Results indicate that it is indeed possible to increase the VPSA unit performance. This modification was very profitable since a $2 \%$ gain in $\mathrm{CH}_{4}$ recovery was obtained for each additional $10 \%$ recycled fraction. However, this recycling led to a decrease in productivity since the recycled gas substitutes the feed flow rate.

The trade-off between sufficient $\mathrm{CH}_{4}$ recovery ( $>$ 91.5\%), specific energy consumption lower than $0.35 \mathrm{kWh} / \mathrm{Nm}^{-3}$ and acceptable productivity is reached for a $60 \%$ recycling of the second purge of the cycle. The main configuration characteristics of the optimized cycle ( 5 columns, 3 equalization steps, recycling of at least half of the second purge) are a priori acceptable in an industrial application.

\section{Acknowledgements}

The authors are grateful to Air Liquide for financial support.

\section{References}

Augelletti, R., Conti, M., Annesini, M.C.: Pressure swing adsorption for biogas upgrading. A new process configuration for the separation of biomethane and carbon dioxide. Journal of Cleaner Production. 140, 1390-1398 (2017). https://doi.org/10.1016/j.jclepro.2016.10.013

Canevesi, R.L.S., Andreassen, K.A., Silva, E.A., Borba, C.E., Grande, C.A.: Evaluation of simplified pressure swing adsorption cycles for bio-methane production. Adsorption. 25, 783-793 (2019). https://doi.org/10.1007/s10450019-00049-x

Cavenati, S., Grande, C., Rodrigues, A.: Separation of CH 4 / CO 2 / N 2 mixtures by layered pressure swing adsorption for upgrade of natural gas. Chemical Engineering Science - CHEM ENG SCI. 61, 3893-3906 (2006). https://doi.org/10.1016/j.ces.2006.01.023

Cavenati, S., Grande, C.A., Rodrigues, A.E.: Upgrade of Methane from Landfill Gas by Pressure Swing Adsorption. Energy Fuels. 19, 2545-2555 (2005). https://doi.org/10.1021/ef050072h

Da Silva, F.A., Silva, J.A., Rodrigues, A.E.: A General Package for the Simulation of Cyclic Adsorption Processes. Adsorption. 5, 229-244 (1999). https://doi.org/10.1023/A:1008974908427

Effendy, S., Xu, C., Farooq, S.: Optimization of a Pressure Swing Adsorption Process for Nitrogen Rejection from Natural Gas. Ind. Eng. Chem. Res. 56, 5417-5431 (2017). https://doi.org/10.1021/acs.iecr.7b00513

Erden, L., Ebner, A.D., Ritter, J.A.: Separation of Landfill Gas CH4 from N2 Using Pressure Vacuum Swing Adsorption Cycles with Heavy Reflux. Energy Fuels. 32, 3488-3498 (2018). https://doi.org/10.1021/acs.energyfuels.7b03534

Fougerit, V., Pozzobon, V., Pareau, D., Théoleyre, M.-A., Stambouli, M.: Experimental and numerical investigation binary mixture mass transfer in a gas - Liquid membrane contactor. Journal of Membrane Science. 572, 1-11 (2019). https://doi.org/10.1016/j.memsci.2018.10.042

Grande, C.A., Blom, R.: Utilization of Dual-PSA Technology for Natural Gas Upgrading and Integrated CO2 Capture. Energy Procedia. 26, 2-14 (2012). https://doi.org/10.1016/j.egypro.2012.06.004

Grande, C.A., Rodrigues, A.E.: Biogas to Fuel by Vacuum Pressure Swing Adsorption I. Behavior of Equilibrium and Kinetic-Based Adsorbents. Ind. Eng. Chem. Res. 46, 4595-4605 (2007). https://doi.org/10.1021/ie061341+ 
Khunpolgrang, J., Yosantea, S., Kongnoo, A., Phalakornkule, C.: Alternative PSA process cycle with combined vacuum regeneration and nitrogen purging for $\mathrm{CH} 4 / \mathrm{CO} 2$ separation. Fuel. 140, 171-177 (2015). https://doi.org/10.1016/j.fuel.2014.09.100

Knaebel, K.S.: Multi-stage adsorption system for gas mixture separation, https://patents.google.com/patent/US8211211B1/en?oq=Knaebel\%2c+K.+S.+MultiStage+Adsorption+System+for+Gas+Mixture+Separation.+Patent+US8211211+B1\%2c+2012., (2012)

Olajossy, A., Gawdzik, A., Budner, Z., Dula, J.: Methane Separation from Coal Mine Methane Gas by Vacuum Pressure Swing Adsorption. Chemical Engineering Research and Design. 81, 474-482 (2003). https://doi.org/10.1205/026387603765173736

Poulleau, J.: Caractérisation des BIOGAZ Bibliographie Mesures sur sites. 82 (2002)

Qinglin, H., Farooq, S., Karimi, I.: Binary and Ternary Adsorption Kinetics of Gases in Carbon Molecular Sieves. Langmuir. 19, (2003). https://doi.org/10.1021/la0270791

Qinglin, H., Farooq, S., Karimi, I.A.: Prediction of binary gas diffusion in carbon molecular sieves at high pressure. AIChE Journal. 50, 351-367 (2004). https://doi.org/10.1002/aic.10032

Radhakrishnan, K.: Description and Use of LSODE, the Livermore Solver for Ordinary Differential Equations. 124

Rasi, S.: Biogas composition and upgrading to biomethane. (2009)

Rasi, S., Veijanen, A., Rintala, J.: Trace compounds of biogas from different biogas production plants. Energy. 32, 1375-1380 (2007). https://doi.org/10.1016/j.energy.2006.10.018

Reinhold, H.E., D’Amico, J.S., Knaebel, K.S.: Natural gas enrichment process, https://patents.google.com/patent/US5536300A/en, (1996)

Rocha, L.A.M., Andreassen, K.A., Grande, C.A.: Separation of CO2/CH4 using carbon molecular sieve (CMS) at low and high pressure. Chemical Engineering Science. 164, 148-157 (2017). https://doi.org/10.1016/j.ces.2017.01.071

Ruthven, D.M.: Principles of Adsorption and Adsorption Processes. John Wiley \& Sons (1984)

Ruthven, D.M.: Diffusion of oxygen and nitrogen in carbon molecular sieve. Chemical Engineering Science. 47, 43054308 (1992). https://doi.org/10.1016/0009-2509(92)85108-N

Ryckebosch, E., Drouillon, M., Vervaeren, H.: Techniques for transformation of biogas to biomethane. BIOMASS \& BIOENERGY. 35, 1633-1645 (2011). http://dx.doi.org/10.1016/j.biombioe.2011.02.033

Santos, M.S., Grande, C.A., Rodrigues, A.E.: New cycle configuration to enhance performance of kinetic PSA processes. Chemical Engineering Science. 66, 1590-1599 (2011). https://doi.org/10.1016/j.ces.2010.12.032

Shafeeyan, M.S., Wan Daud, W.M.A., Shamiri, A.: A review of mathematical modeling of fixed-bed columns for carbon dioxide adsorption. Chemical Engineering Research and Design. 92, 961-988 (2014). https://doi.org/10.1016/j.cherd.2013.08.018

Sircar, S.: Pressure Swing Adsorption. Applied Catalysis. 46, (2002). https://doi.org/10.1021/ie0109758

Voss, C.: Applications of Pressure Swing Adsorption Technology. Adsorption. 11, 527-529 (2005). https://doi.org/10.1007/s10450-005-5979-3

Warren, K.: A techno-economic comparison of biogas upgrading technologies in Europe. (2012) 


\title{
Biomethane production by adsorption technology: New cycle development, adsorbent selection and process optimization
}

\author{
Najib Chouikhi ${ }^{1,2} \cdot$ Federico Brandani $^{2} \cdot$ Pluton Pullumbi $^{2} \cdot$ Patrick Perre $^{1,3} \cdot$ François Puel $^{1}$
}

\section{Supplementary Material}

\section{Reference cycle description}

The reference cycle considered in this study is well studied in $\mathrm{CO}_{2}$ capture and is a four column and an 8-step cycle. The sequence of the steps of the cycle for a single bed is reported in Figure 1.

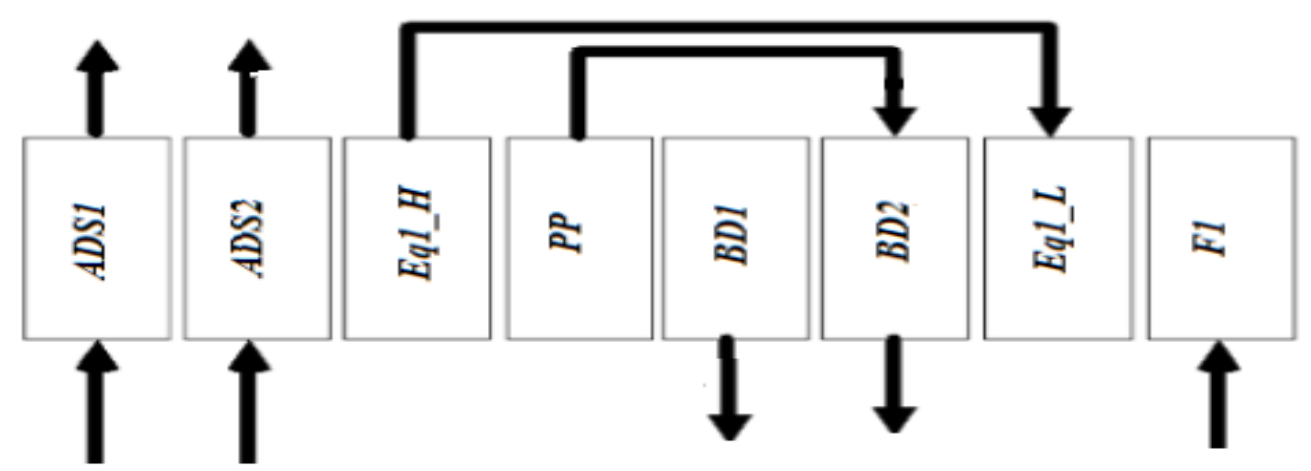

Figure 10 Reference cycle representation based on single bed sequence of 8 steps

(ADS1) Adsorption1, (ADS2) Adsorption2, (Eq1_H) equalization-depressurization, $(P P)$ purge provide, (BD) Blowdown, (Eq1_L) equalization-pressurization, $(F)$ Feed.

The 8 steps are regrouped into 4 phases:

The Production phase (PHASE 1) is composed of:

o Two adsorption production steps (ADS1; ADS2) wherein the biogas is fed to the bottom of the column at high pressure ( 8 bara), the adsorption occurs, and a $\mathrm{CH}_{4}$-rich product is obtained at the top of the column (pure biomethane).

\section{Affiliations}

Francois

francois.puel@centralesupelec.fr

1 LGPM, Laboratoire de Génie des Procédés et Matériaux, CentraleSupélec, Université Paris-Saclay, 3 rue Joliot-Curie, 91192 Gif-surYvette, France

2 Air Liquide, Paris Innovation Campus. 1, chemin de la Porte des Loges, 78350 Les Loges en Josas, France

3 LGPM, Laboratoire de Génie des Procédés et Matériaux, CentraleSupélec, Université Paris-Saclay, SFR Condorcet FR CNRS 3417, Centre Européen de Biotechnologie et de Bioéconomie (CEBB), 3 rue des Rouges Terres 51110 Pomacle, France 
The Depressurization phase (PHASE 2) is composed of the following sequence steps:

o One equalization depressurization step $\left(\mathrm{Eq} 1 \_H\right)$, wherein the high-pressure gas present in the interstitial spaces of column 2 at the end of the adsorption phase is used to partially pressurize columns 4 which is in the Equalization pressurization step Eq1 L.

o One purge provides step (PP) wherein column 2 (opened at the top and closed at the bottom) is connected to column 3 (which is in the BD2) to depressurize the column and push the impurities.

The Regeneration phase (PHASE 3 ) is composed of the following sequence steps:

o One blowdown step (BD1) wherein the regeneration is started. Column 3 (closed in the top and opened in the bottom) is depressurized until atmospheric pressure to start the desorption of the $\mathrm{CO}_{2}$.

o One blowdown step (BD2), wherein the regeneration is completed by feeding the column at low pressure using a vacuum pump.

The Pressurization phase (PHASE 4) is composed of the following sequence steps:

o An equalization pressurization step (Eq1_L), wherein column 4 is partially pressurized with the highpressure gas extracted from column 2 during the Eq1_H step.

o One pressurization step (F1), wherein the column is pressurized with the biogas feed.

The simulation results of the reference (Table 1) cycle showed that $26 \%$ of the methane was lost during the two blowdown steps.

Table 8 Simulation results of the reference cycle

\begin{tabular}{cccccccccc}
\hline $\begin{array}{c}\text { Run } \\
\#\end{array}$ & $\begin{array}{c}\mathrm{P}_{\text {ads }} \\
(\text { bara })\end{array}$ & $\begin{array}{c}\mathrm{P}_{\text {des }} \\
(\text { bara })\end{array}$ & $\begin{array}{c}\text { Cycle } \\
\text { duration(s) }\end{array}$ & $\begin{array}{c}\text { Recycle } \\
\text { ratio } \\
(\%)\end{array}$ & $\begin{array}{c}\text { Methane } \\
\text { Purity }(\%)\end{array}$ & $\begin{array}{c}\text { Methane } \\
\text { Recovery } \\
(\%)\end{array}$ & $\begin{array}{c}\text { Productivity } \\
\left(\mathrm{Nm}^{3} /\left(\mathrm{h} . \mathrm{m}^{3}\right)\right)\end{array}$ & $\begin{array}{c}\text { Biogas } \\
\text { flowrate } \\
\left(\mathrm{Nm}^{3} / \mathrm{h}\right)\end{array}$ & $\begin{array}{c}\text { Specific energy } \\
\text { consumption } \\
\left(\mathrm{kWh} / \mathrm{Nm}^{3}\right)\end{array}$ \\
\hline 1 & 8 & 0.5 & 680 & 0 & 97 & 74.3 & 32 & 701 & 0.31 \\
\hline
\end{tabular}

Figure 2 shows the pressure profile and the mole fractions of $\mathrm{CO}_{2}$ and $\mathrm{CH}_{4}$ in the gas phase at the bottom of the column. The adsorption pressure remains constant at 8 bara during the adsorption steps (ADS1 and ADS2) which is consistent as the pressure is a controlled parameter. During the second purge step BD2, a vacuum pump is used to evacuate the $\mathrm{CO}_{2}$. The pressure was reduced to 0.5 bara to create the condition for gas desorption. The molar fraction of methane at the bottom of the column remains constant during the first four steps. This fraction drops from $60 \%$ to $15 \%$ at the end of BD1. During the BD2 step, the methane fraction at the bottom of the column increases to 0.42 , which means that at the end of the $\mathrm{BD} 2,42 \%$ of the purge gas is methane. This explains the low $\mathrm{CH}_{4}$ recovery level of the process.

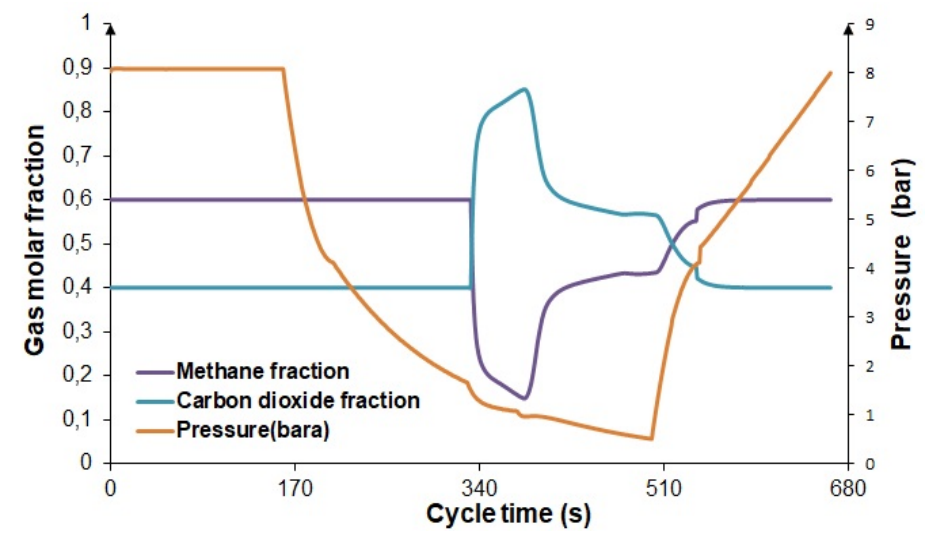

Figure 11 Pressure profile and gas molar fraction at the bottom of the column

Figures $3 \mathrm{a}$ and $3 \mathrm{~b}$ presents respectively the adsorbed amount of $\mathrm{CH}_{4}$ and $\mathrm{CO}_{2}$ at the end of each step as a function of the axial position. The increase of $\mathrm{CH}_{4}$ adsorbed in the $\mathrm{CMS}$ in the axial position reflects the composition of the gas in the column, which is increasingly purer. The adsorbed quantities of methane at the end of each step are similar over the 
entire height of the column. This unexpected profile means that once the cyclic equilibrium state is reached, the already adsorbed methane does not desorb during the purge phase. The adsorption profile of $\mathrm{CO}_{2}$ is reverse with that of $\mathrm{CH}_{4}$. The highest values of adsorbed $\mathrm{CO}_{2}$ are found at the bottom of the column. Unlike $\mathrm{CH}_{4}$, the variations in the amount of $\mathrm{CO}_{2}$ adsorbed between steps are significant, reflecting the greater kinetic ability of this component to adsorb and desorb with this adsorbent.
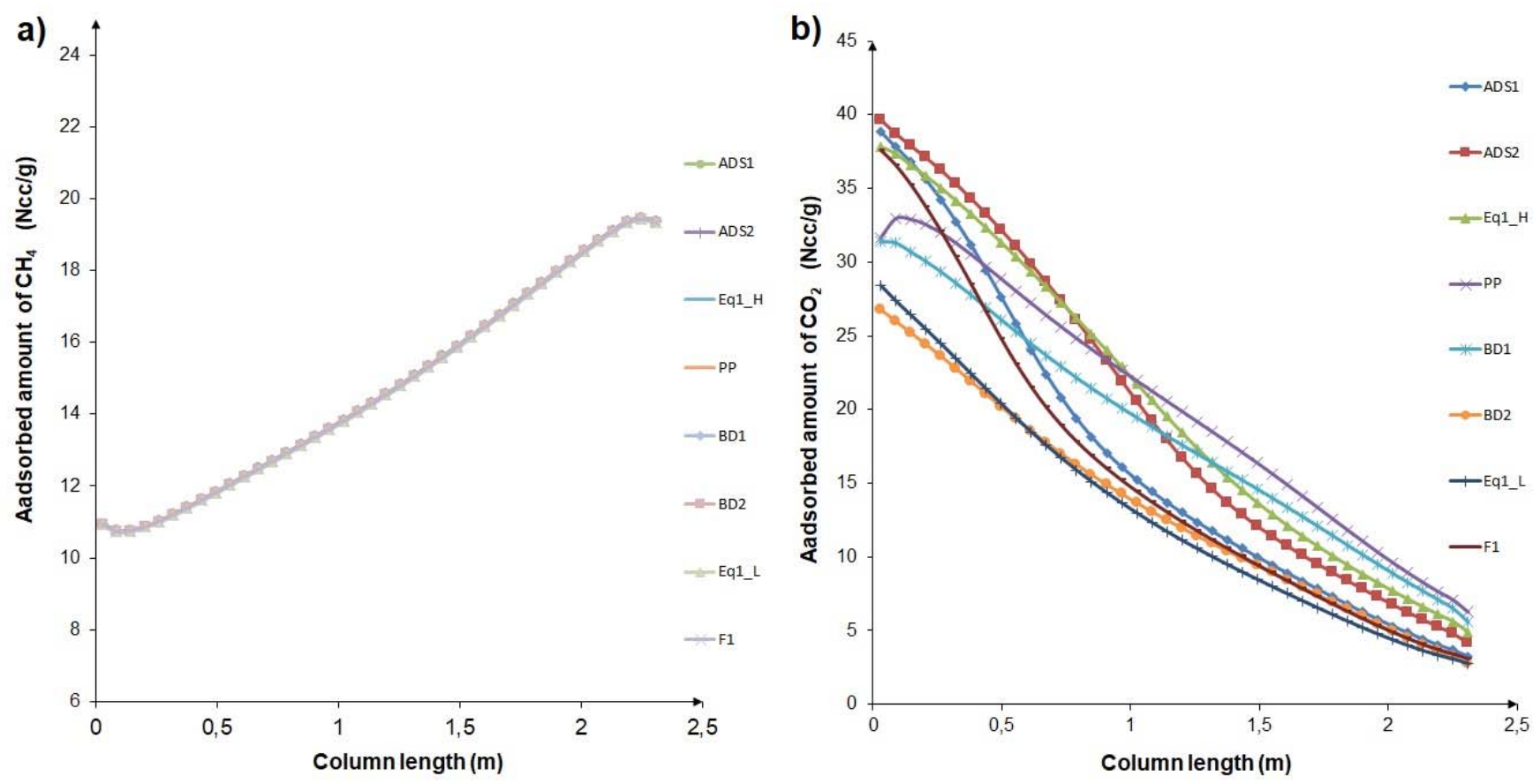

Figure 12 Adsorbed amount of $\mathrm{CH}_{4}$ and $\mathrm{CO}_{2}$ at the end of each step as a function of the axial position with the reference cycle a) $\mathrm{CH}_{4}$ adsorbed amount, b) $\mathrm{CO}_{2}$ adsorbed amount

\section{Case with low desorption pressure $\left(P_{\text {des }}=0.1\right.$ bara $)$ for the new cycle}

A new cycle with 5 columns and 15 steps is discussed in the article. Additional simulations (see Table 2) were performed using a lower desorption pressure level (0.1 bara) for the BD2_ref step to see its impact on the adsorbed methane quantity profile.

The impact of this operating parameter was not significant on the adsorbed amount of methane profile at the end of each step (see Figure 4), only the maximum amount of methane adsorbed was decreased to $17.3 \mathrm{Ncc} / \mathrm{g}$. This means that even with a desorption pressure of 0.1 bara the desorption of methane from the CMS is not greatly improved. Finally, it should be noted that the diminution of the desorption pressure significantly increases the methane recovery rate to $97 \%$. This is also accompanied by an increase in the specific energy of biomethane production $(0.56 \mathrm{kWh} / \mathrm{Nm} 3)$.

Table 9 Simulation results of the new cycle (case with $P_{-}$des $=0.1$ bara)

\begin{tabular}{|c|c|c|c|c|c|c|c|c|c|}
\hline$\underset{\#}{\text { Run }}$ & $\begin{array}{l}\mathrm{P}_{\text {ads }} \\
\text { (bara) }\end{array}$ & $\begin{array}{l}P_{\text {des }} \\
\text { (bara) }\end{array}$ & $\begin{array}{c}\text { Cycle } \\
\text { duration(s) }\end{array}$ & $\begin{array}{c}\text { Recycle } \\
\text { ratio } \\
(\%)\end{array}$ & $\begin{array}{l}\text { Methane } \\
\text { Purity (\%) }\end{array}$ & $\begin{array}{l}\text { Methane } \\
\text { Recovery } \\
(\%)\end{array}$ & $\begin{array}{l}\text { Productivity } \\
\left(\mathrm{Nm}^{3} /\left(\mathrm{h}^{3} \mathrm{~m}^{3}\right)\right)\end{array}$ & $\begin{array}{l}\text { Biogas } \\
\text { flowrate } \\
\left(\mathrm{Nm}^{3} / \mathrm{h}\right)\end{array}$ & $\begin{array}{l}\text { Specific energy } \\
\text { consumption } \\
\left(\mathrm{kWh} / \mathrm{Nm}^{3}\right)\end{array}$ \\
\hline
\end{tabular}

New Cycle

\begin{tabular}{llllllllll}
\hline 11 & 8 & 0.1 & 725 & 60 & 97 & 97.0 & 22.3 & 971 & 0.56
\end{tabular}



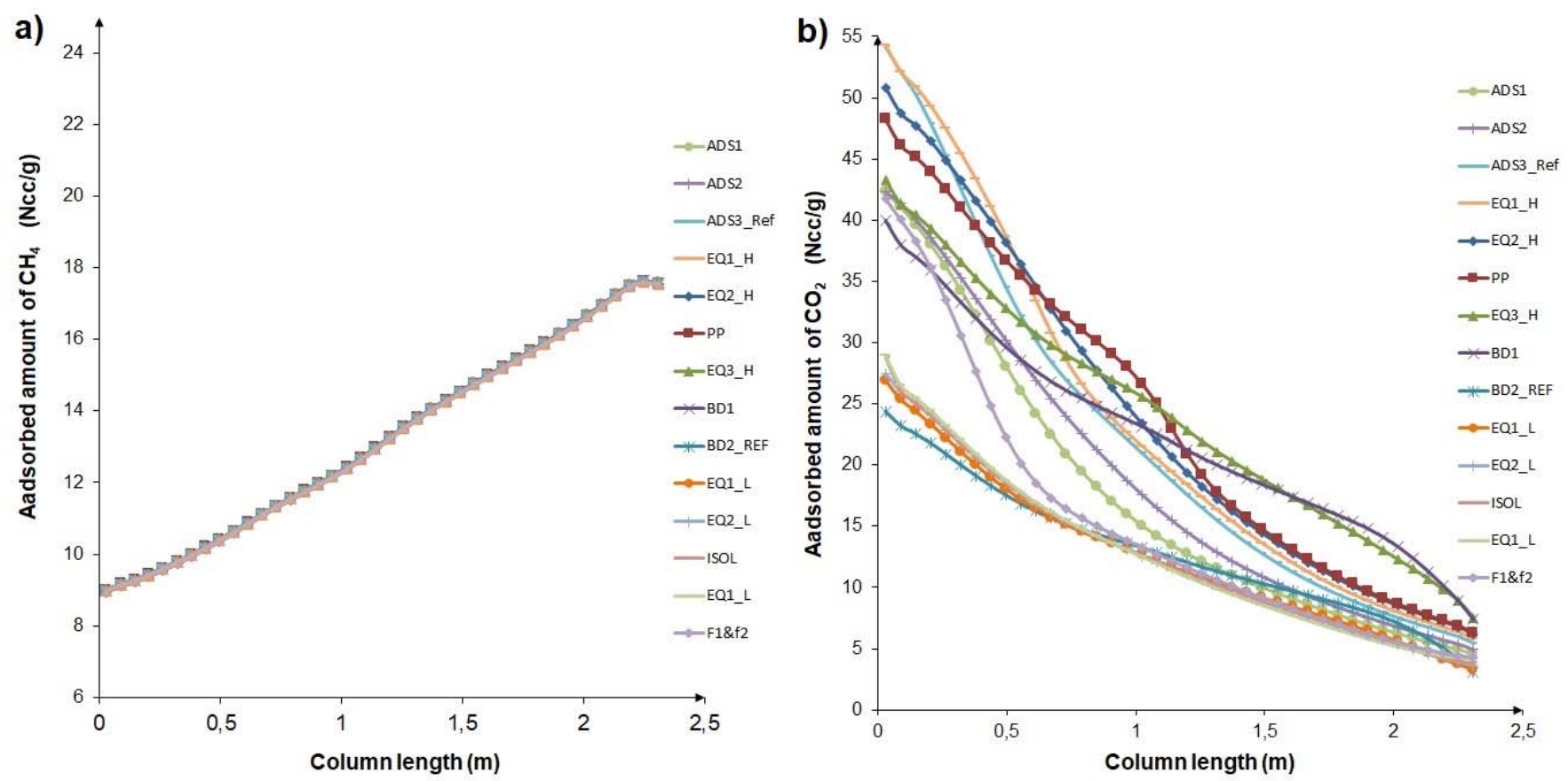

Figure 13 Adsorbed amount of $\mathrm{CH}_{4}$ and $\mathrm{CO}_{2}$ at the end of each step as a function of the axial position with 60\% recycling and P_des=0.1bara a) $\mathrm{CH}_{4}$ adsorbed amount with $60 \%$ recycling, b) $\mathrm{CO}_{2}$ adsorbed amount with $60 \%$ recycling 